\title{
Production and Characterization of Recombinant Rat Non-Collagen Domain of $\alpha 3$ Chain of Type IV Collagen $\alpha 3$ (IV) NC1 Antigen
}

\author{
Afsana Munni \\ School of Life Science, University of Bedfordshire, Luton, UK \\ Email: afsana.munni@beds.ac.uk \\ Received 1 May 2016; accepted 18 August 2016; published 23 August 2016 \\ Copyright (C) 2016 by author and Scientific Research Publishing Inc. \\ This work is licensed under the Creative Commons Attribution International License (CC BY). \\ http://creativecommons.org/licenses/by/4.0/

(c) () D D Den Access

\section{Abstract}

The glomerulonephritis disease is characterized by inflammation of glomeruli or small blood vessels in the kidney that causes kidney diseases. The reason of glomerulonephritis disease is to deposit the anti-GBM auto antibody in the glomerular basement membrane. The type IV collagen is the main component of glomerular basement membrane that has $\alpha 3$ chain of type (IV) collagen of non-collagenous domain which contains $\mathrm{N}$-terminal $7 \mathrm{~S}$ domain, a triple helical collagenous domain and C-terminal non-collagenous glomerular domain (NC1). The amino terminal of $\alpha 3$ (IV) NC1 that induces the Experimental Autoimmuno Glomerulonephritis (EAG) in rat model has been identified. The recombinant rat $\alpha 3$ (IV) NC1 antigen has nine amino acid spans that are consistent with antibody or $T$ cell epitope that induces in EAG. The research is carried out on the recombinant rat $\alpha 3$ (IV) NC1 production, purification, quantification, and characterization. The circulation of anti-GBM antibody in glomerular basement membrane can be measured by the ELISA assay. In addition, the recombinant rat antigen is secreted in HEK293 cell supernatant that is purified by Anti-FLAG M2 monoclonal IgG antibody affinity column and characterized and quantified by SDS-PAGE gel electrophoresis and Western blotting techniques.

\section{Keywords}

Auto-Immuno Kidney Disease, Glomerulonephritis Disease, Glomerular Basement Membrane, $\alpha 3$ (IV) NC1-Non-Collagen Domain of $\alpha 3$ Chain of Type IV Collagen $\alpha 3$ (IV), Antibody(Ab), Antigen (Ag), Anti Glomerular Basement Membrane, Experimental Autoimmune Glomerulonephritis, Enzyme-Linked Immunosorbent Assay (ELISA), Human Embryonic Kidney (HEK), Ig-Immunoglobulin (IgG, IgA), IgAN-IgA nephropathy 


\section{Central Hypothesis and Aim}

The reason of autoimmune disease and how it develops still remains undiscovered whereas auto-antigen complementarity theory provides an alternative mechanism of autoimmune disease. The overall objective of this research is identified, selected, cultured, purified, and characterized the desired recombinant rat antigen. The central interest is to find the antigen and antibody interaction and how glomerulonephritis disease is developed. For the investigation of Anti-GBM disease, rat is an ideal model to analysze auto-antigen complementarity. The Anti-GBM disease is initiated by exposure of protein or recombinant peptides according to shape, sequence of $\alpha 3$ (IV) NC1 anti-GBM auto-antigen. The Anti-GBM antibody response against protein or peptide complementary is determined by the $\alpha 3$ (IV) NC1 anti-GBM auto-antigen epitopes. The main hypotheses are:

1) To understand the circulating antibodies that can recognize $\alpha 3$ (IV) NC1 epitopes.

2) To understand Anti-GBM disease immunized in a rat model with a recombinant $\alpha 3$ (IV) NC1 anti-GBM auto-antigen.

In nutshell, the purpose of research is to understand the autoimmune response of immunization with purified recombinant form of antigen. The recombinant rat $\alpha 3$ (IV) NC1 domain was cloned and sequencing and transfected into HEK293 cells and secreted into cell supernatant as a fusion protein with FLAG epitope. Recombinant $\alpha 3$ was purified with Anti-FLAG affinity gel and measured the presence of antigen by column chromatography. The optical density of elution profile determined the protein concentration at $280 \mathrm{~nm}$. SDS-PAGE and western blotting techniques are used for determination of quantity of antigen and conformation of antigen antibody bonding. The Enzyme Linked Immuno-Sorbent Assay (ELISA) is used for detecting the circulation and deposition of Anti-GBM autoantibodies. The result portion is carried out by the recombinant rat $\alpha 3$ cultured, column chromatography for elution of antigen that is bound to the monoclonal M2 antibody, SDS PAGE gel electrophoresis which determines the quantification of elution protein molecular weight, and Western blotting techniques for the confirmation of proteins using secondary monoclonal antibody. The discussion part contains the clarification and scientific reason according to obtained results.

\section{Introduction}

\subsection{General Introduction of Kidney Functions and Kidney Disease}

The major functions of kidneys are preparing urine in which toxic metabolic products (waste product) and water are eliminated. Kidneys release different types of hormones such as renin (circulates blood pressure), erythropoietin (regulates red blood cells), activated form of Vitamin D for maintain normal bone structure, electrolyte concentration maintenance, regulate acid-base balance and control osmotic pressure of body fluids. The kidneys have renal artery, nephron, glomerulus, tubule, capillaries, collecting duct parts. The unfiltered blood first passes the kidney through renal artery and is filtered by nephron. The nephron is main filtered parts of kidneys and each kidney has about one million nephrons. The nephron consists of glomerulus, tubules, capillaries, and collecting duct. Glomerulus plays an important role in efficient filtration where small molecules can pass through but large molecules like blood cells, proteins can’t be able to pass. The filtered blood exits from glomerulus and enters the tubules and collecting ducts. Tubules and collecting ducts have very complex mechanisms with various loops that can filter further for reabsorbing salts, nutrients for body's need. The collecting duct is connected to the ureter where urine flows out to bladder and the filtered blood flows out from renal vein.

From Figure 1, the general part of kidney is shown with functioning properties where each and every part has responsible for kidney disease if inappropriate functions.

The common kidney diseases are polycystic kidney disease, Hypertensive nephrosclerosis, Glomerulonephritis or glomerulosclerosis, Urinary Tract Infection (UTI), kidney stones, Diabetic kidney disease, Analgesic nephropathy. The anti-glomerular basement membrane (Anti-GBM) is the only glomerular disease that identically identifies that the antibodies develop against a native renal antigen.

\subsection{Background of Autoimmune Diseases}

The autoimmune diseases can be defined as the abnormal function of body immune system that produces antibodies (T-cell and B-cell autoreactivity) against normal host cells and tissues. The reasons of autoimmune diseases are not well understand yet, but may be related to the combination of genetic and environmental disorder such as bacteria, viruses, toxins, genetic disorders. In 1997 a meta-analysis estimated around 30 years record 


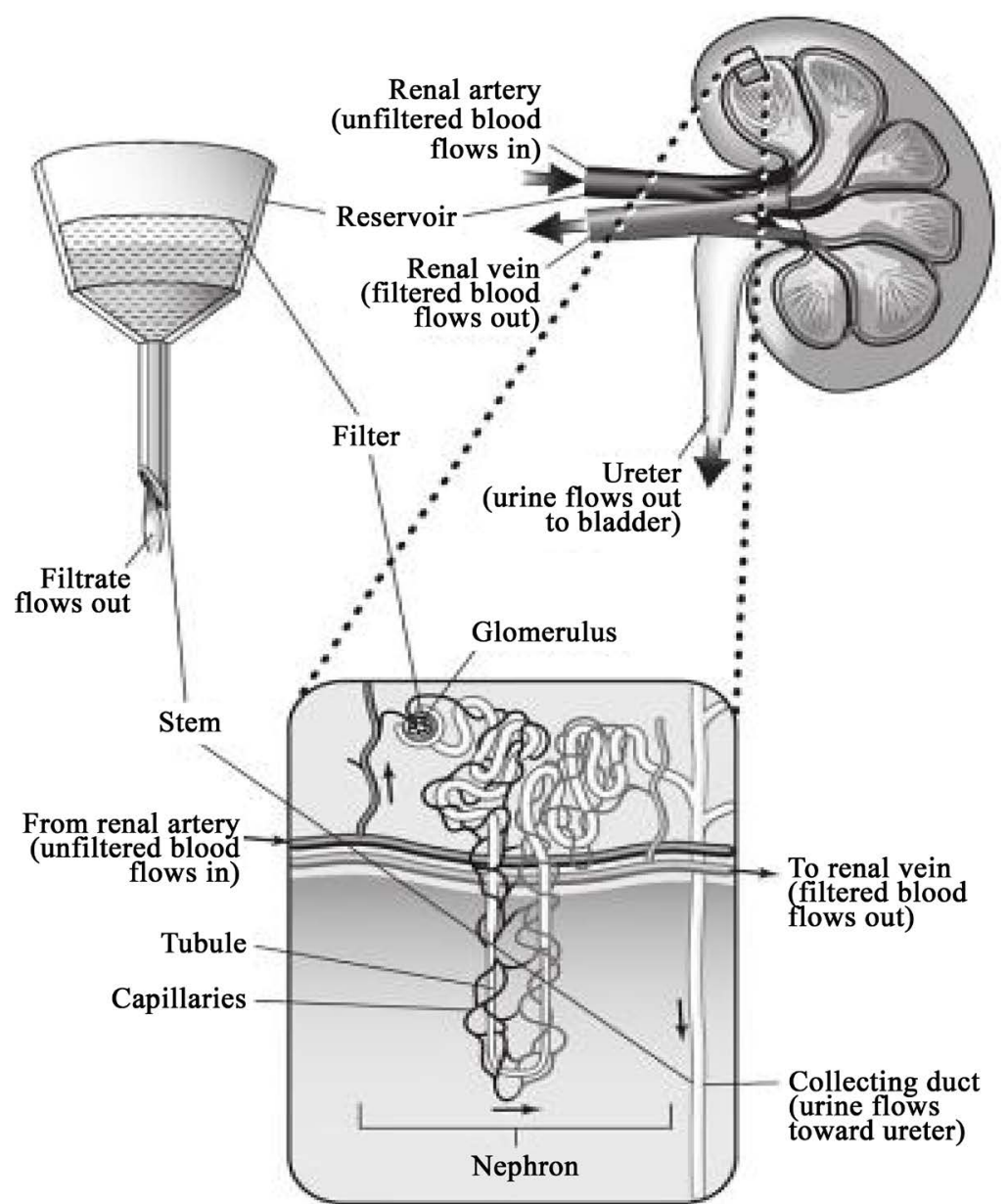

Figure 1. The functioning properties of the kidney (Source: Kidney disease: A guide for living (Walter A. Hunt)).

that 3.2\% American had been diagnosed one of 24 autoimmune diseases. The most common autoimmune diseases are type-I diabetes mellitus, systemic lupus erythematosus, multiple sclerosis, asthma, psoriasis, glomerulonephritis, pulmonary fibrosis. The most common therapy of autoimmune diseases is immunosuppressive and/ or cytotoxic, but the curative percentage is very low and also lifelong treatment is usually required. In particular, combinations of altered production or activation of antibodies played the major role of primary and progression of autoimmune diseases especially in several glomerulonephritis. Anti-glomerular basement membrane disease (Anti-GBM), anti-neutrophil cytoplasmic antibody-associated diseases, IgAN, type-II membranoproliferative glomerulonephritis diseases are definitively associated with antibodies against host proteins. Anti-GBM disease is the injury of small blood vessels or capillary attacked by autoantibodies. When glomeruli inflamed, it had easy passage of bloods and proteins into urine. The exact reason of glomerulonephritis is not identified properly but it is clearly involved in immunological mechanism [1]. The glomerular capillaries wall has thin membrane, under normal condition; the endothelium cells protect the lower membrane from moving antibodies. Smoking, hydrocarbons, infection, metal dust etc. can cause leakiness of cell layer so that the lower membrane becomes more accessible to Anti-GBM antibodies and binds to the capillary basement membrane such as nephritis. Therefore, the white blood cells attack the vessels results of inflammation. Glomerulus is tiny blood vessels that filter blood to form urine. The auto antibody IgG is against the goodpasture's antigen and comprises the $\alpha 3$ (IV) NC1, a molecule with restricted tissue distribution only found in specialized basement membrane of renal glomerulus and the alveoli [1]-[3].

\subsection{Glomerulonephritis}

Glomerulonephritis (GN) is known as glomerular nephrities, characterized by inflammation of the glomeruli or 
small blood vessels in the kidney, caused by kidney diseases. Glomerulonephritis is the direct cause of capillary wall damage and disturbances in normal glomerular function, gradually loss the filtration capacity and excessive transfer for hematuria and proteinuria. The body's immune system reacts with antigen and antibody complexes like bind to specific antigen or fragment of antigens by B cells (antibodies) or T cells (T cells receptor) or nonspecific mediation of tissue damage. Historically, depositioning of antibodies within the glomeruli involved the immune system of glomerulonephritis. It can be explained by antibody mediated mechanism either by direct reaction glomerular antigens (Anti-GBM disease) or by deposition of antibodies in glomeruli.

According to Figure 2, the images can demonstrate the mechanism of Anti-GBM antibody in glomerular basement membrane.

From Figure 3, the image can demonstrate the difference between the normal and affected glomerulus. The image of left side has normal glomerulus whereas right one has inflammation of glomerulus.

\title{
Different Types Glomerulonephritis Diseases
}

There are two classes of glomerulonephritis: non-proliferative glomerulonephritis and proliferative glomerulonephritis. The non-proliferative type of glomerulonephritis is characterized by the number of cell in the glomeruli (lack of hypercellularity), divided into three sub-division: Minimal change GN, Focal Segmental Glomeru-

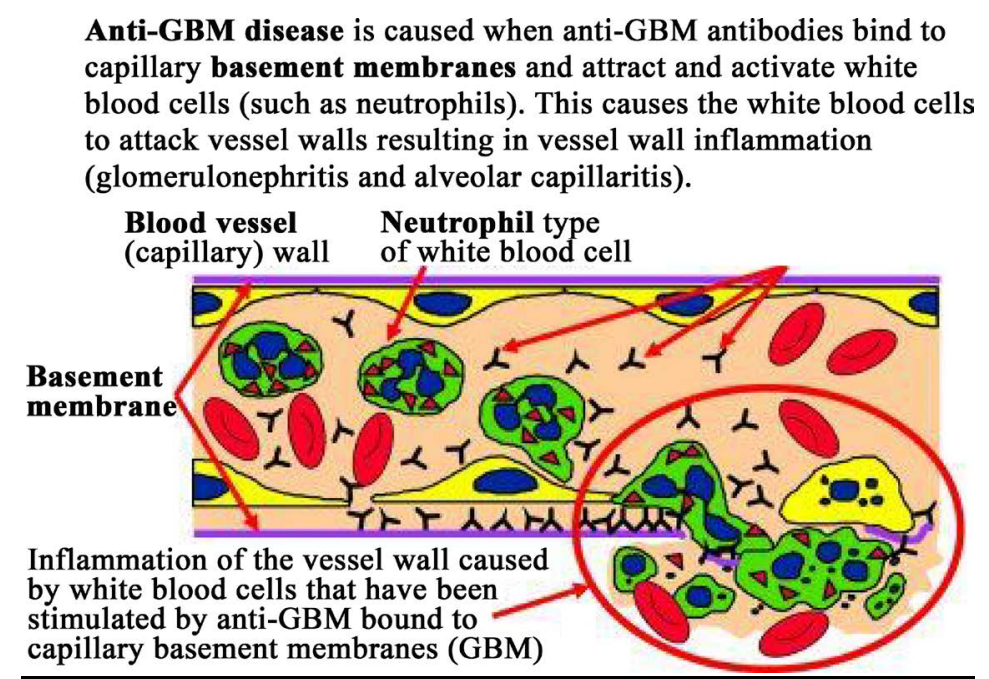

Figure 2. Inflammation of Glomerular Basement Membrane caused by anti-GBM antibodies bind to the capillary basement membrane (Source: Immunology of anti-glomerular basement membrane disease. (Alan D. Salama and Charles D. Pusey)).

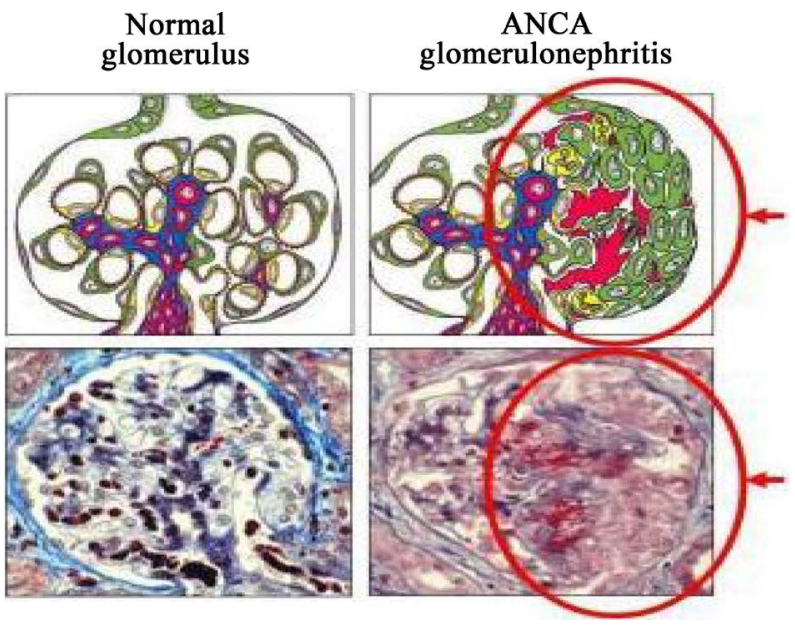

\author{
Diagram of \\ glomerular \\ inflammation \\ (glomerulonephritis) \\ Glomerular \\ inflammation \\ (glomerulonephritis) \\ in a kidney biopsy \\ from a patient with \\ ANCA vasculitis
}

Figure 3. Diagram of normal glomerulus and after affect the antiGBM antibodies glomerulus (Glomerulonephrities) (Source: Immunology of anti-glomerular basement membrane disease (Alan D. Salama and Charles D. Pusey)). 
losclerosis (FSGS) and Membranous GN. Minimal Change GN causes mainly 80\% of nephrotic syndrome in children, visible only electron microscope, treatment is massive fluid supply as well as steroids. Focal Segmental Glomerulosclerosis (FSGS): primary, secondary to reflux nephropathy, nephrotic syndrome with impaired renal function. The pathological treatment is sclerosis of glomerulus and hyalinization of the feeding arterioles. The membrane glomerulonephritis is thickened glomerular basement membrane without hypercellular glomerulus, diffuse granular uptake of IgG that affect the tubulus of the kidney. The treatment is corticosteroids. The proliferative glomerulonephritis is increased the number of glomerulus cells (hypercellular)- presents the nephritic syndrome and end stage of renal failure. IGA nephropathy or Berger's disease is the most common type of proliferative glomerulonephritis disease. This disease causes visible bloody urine or haematuria. ACE inhibitors are the main treatment of this disease. Post infection glomerulonephritis is characterized any bacterial infection and treatment is based on findings and streptococcal titers in the blood can be helpful as well. Membranoproliferative glomerulonephritis present the nephrotic syndrome although nephritic with massive progression of renal failure. The Rapidly progression glomerulonephritis or Crescentic GN is a poor prognosis with rapid progression of kidney failure, treatment is steroid therapy.

In Figure 4, is classified the glomerulonephritis disease and also included the reasons that are responsible for different types od glomerulonephritis diseases.

\subsection{Goodpasture's Disease}

The American pathologist Ernest Goodpasture [4] of Vanderbit University was first described 18-year-old man with renal failure and pulmonary hemorrhage at early $20^{\text {th }}$ century and based on this report in 1958, Stanton and Tange [5] used the Goodpasture's syndrome in their description as a series of men with glomerulonephritis and hemoptysis. However, originally the goodpasture's patient had focal necrosis of the spleen and intestinal hemorrhage. Therefore, goodpasture's patient did not have that disease that has now become known as Goodpas-

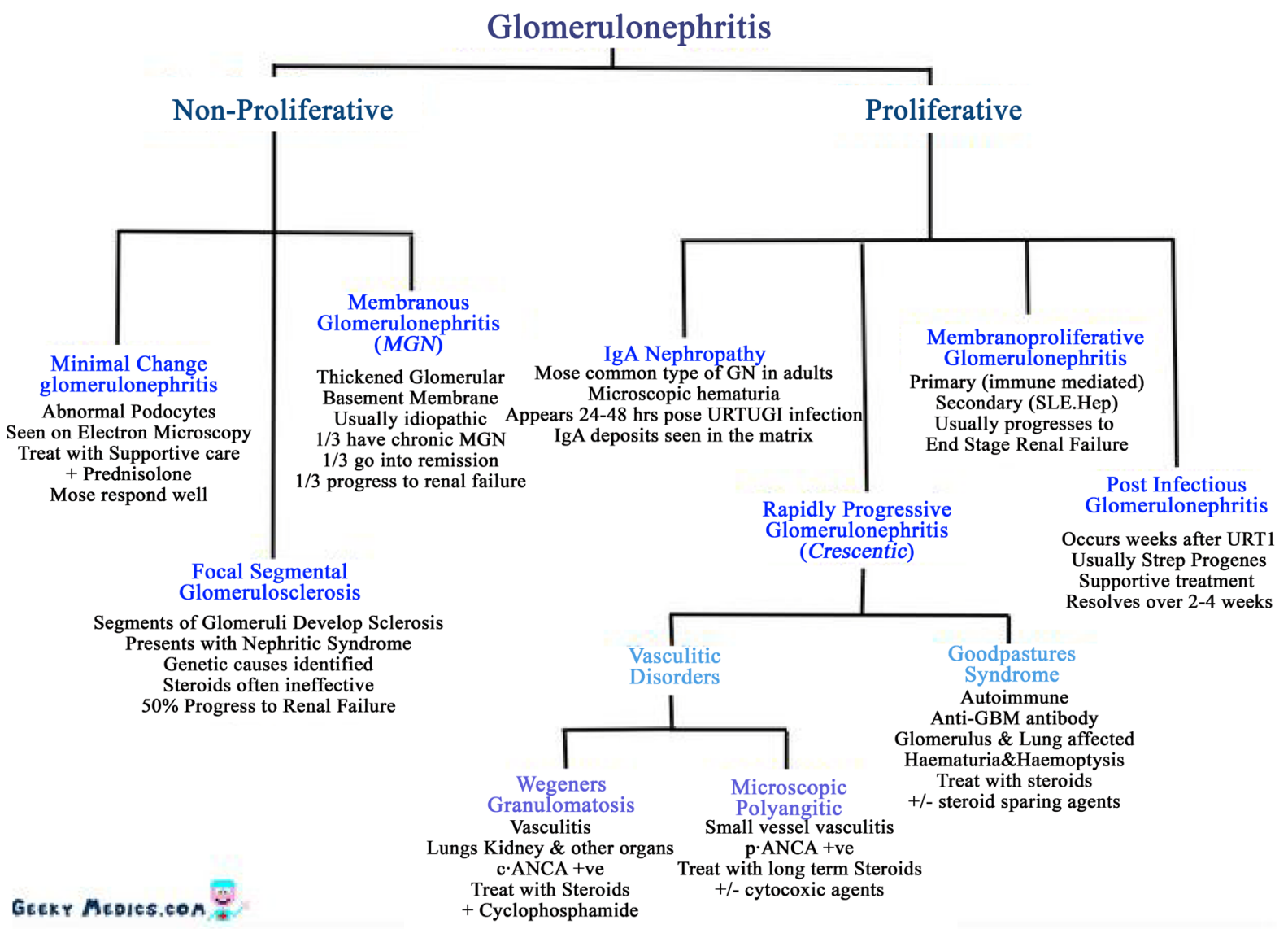

Figure 4. Classification of Glomerulonephritis (Source: Geeky Medics.com). 
ture's syndrome but now it is established as Goodpasture's diseases or Goodpasture syndrome or anti glomerular basement membrane disease. The several diseases are now reported to causes of immune system attack a specific part of kidney and lung, goodpasture's antigen. Thus, the autoimmunological disease is the inflammation and cell proliferation in the glomerulus that antibody attack the kidney and lung [2] [4]. Goodpasture's disease is a rare, about 1 case per million people/year in white European population and also occurred in patients as young as 4 and as old as 80 and age range around 18 - 30 and 50 - 65 man and women are equally affected. The investigation of pathogenesis and biochemical, Goodpastur's disease is a rare prototype example and evaluation of biological processes. It was demonstrated initially pulmonary hemorrhage with glomerulonephritis and subsequent studies included the liner distribution of antibodies along glomerular and alveolar basement membranes. Further investigation proved that autoantibodies eluted from the kidneys and linear deposition of the glomerular basement membrane.

Therefore, Goodpasture's syndrome refers to the triad of pulmonary hemorrhage and glomerulonephritis in the presence of circulating antibodies in the glomerular basement membrane. The intensive studied described that the non-collagenous domain of the $\alpha 3$ chain of type IV collagen, $\alpha 3$ (IV) NC1 [3] [6] as the antigenic epitope that initiate the complex autoimmune reaction. Moreover, previous studied suggested that only humoral mechanisms caused for autoimmune process but recently discovered cellular immune process plays an important role of pathogenesis of goodpasture's disease. Therefore, Goodpasture's syndrome is indicated as a rare or "orphan" disorder.

The presence of anti-GBM autoantibody is one of the most important characteristic features of Goodpasture's disease. Goodapaster's disease is identified by the binding of immunoglobulin IgG autoantibodies to glomerular basement membrane that increase the inflammation of glomerular. Immunoglobulin G1 subtypes are major autoantibodies although most women have G4 subtype auto antibody. For humoral immunity, the anti-GBM antibodies bind to the Non collagenous domain of $\alpha 3$ chain of IV type collagen that only found in specialized basement membrane of kidneys, lung, choroid retina [7] [8]. There are many assays to detect the circulation of anti GBM such as immunofluorescence, RIA, ELISA and more recently developed optical biosensor technology.

\section{Biochemistry of Basement Membrane and Collagen}

\subsection{Basement Membrane}

The function of glomerular basement membrane is ultrafiltration of blood plasma by the kidney. Epithelium and endothelium layers are connected to the basement membrane and composed of several large glycoproteins. Basement membrane is composed of collagenous and non-collagenous proteins that provide structural and functional support of cells. The different receptors and signaling mechanisms is the main function of basement membrane component cells [9]. The Non collagenous protein consists of laminin, enactin, perlecan and other minor component. Laminin plays a major role in cell-matrix interaction and other component basement membrane with cell surface recptors. Nidogen or enactin enhances the pulmonary basement membrane function and nidogen and perlecans established the type IV collagen network. In addition, minor components of basement membrane help tissues function and enhance unique interactions with the adjacent cells that promote direct cellular differentiation and functions.

\subsection{History of Non-Collagen Domain of $\alpha 3$ Chain of Type IV Collagen}

In 1966, Kefalides was first isolated collagen IV that belongs to a family of collagenous proteins with at least 25 members. Type IV Collagen is the main component of basement membrane that provides different architectural patterns. There are six different type IV collagen genes that known as $\alpha$ chains $(\alpha 1-\alpha 6)$. COL4A1, COL4A2, COL4A3, COL4A4, COL4A5 and COL4A6 genes encode the six chain of collagen IV, $\alpha 1$ (IV)- $\alpha 6$ (IV) [10] [11] as well as expressed the different stages of embryonic development in basement membrane. The length of Each $\alpha$ chain is $400 \mathrm{~nm}$ and composed of three domains- N-terminal 7S domain (26 kDa, $28 \mathrm{~nm})$, a triple helical collagenous domain (120 kDa, $320 \mathrm{~nm})$ and C-terminal non-collagenous glomerular domain (NC1) (25 kDa, 52 $\mathrm{nm})$. The 7S domain and collagenous domain consist of GLy-X-Y where X and Y present often proline or hydroprolin and lysine and hydroxylysine such as Glycine-proline-hydroxyprolin-lysin-hydroxylysin amino acid sequences. The Noncollagenous domain consists of cysteine-lyesin amino acids but lack of hydroxyproline. This amino acids sequence provides the structural integrity of the collagen promoters and suprastructural. The both 
7S( N-terminal) and NC1(C-terminal)are important for the network formation of type IV collagen. In spite of any permutations, collagen IV can form three sets of triple helical molecules, known as promoters. Promoters are known as the main building block of the collagen type IV that secreted from the cells and assembled with fixed combination of ( $\alpha 1 \alpha 1 \alpha 2)$, ( $\alpha 3 \alpha 4 \alpha 5)$ and probably ( $\alpha 1 \alpha 1 \alpha 5),(\alpha 1 \alpha 2 \alpha 5)$ or $(\alpha 5 \alpha 5 \alpha 6)$.

The NC1 domains have high degree of identical and similar amino acid sequence and 12 cystein residue conserved pattern that form six intra-chain disulfide bonds in NC1.

Figure 5, demonstrate the Non-Collagen domain of $\alpha 3$ chain of type IV collagen identically where six distinct $\alpha$ chain have three triple helical promoters and each promoters has 7S domain at the $\mathrm{N}$-terminal.

From Figure 6, is briefly shown the structure the glomerular basement membrane that interlock to form triple helical.

\subsection{Animal Models}

In order to understand the mechanism of autoimmunity glomerulonephritis or Goodpasture's disease, several animal models have been developed to analyze the antibody and antigen reaction, optimal binding condition for

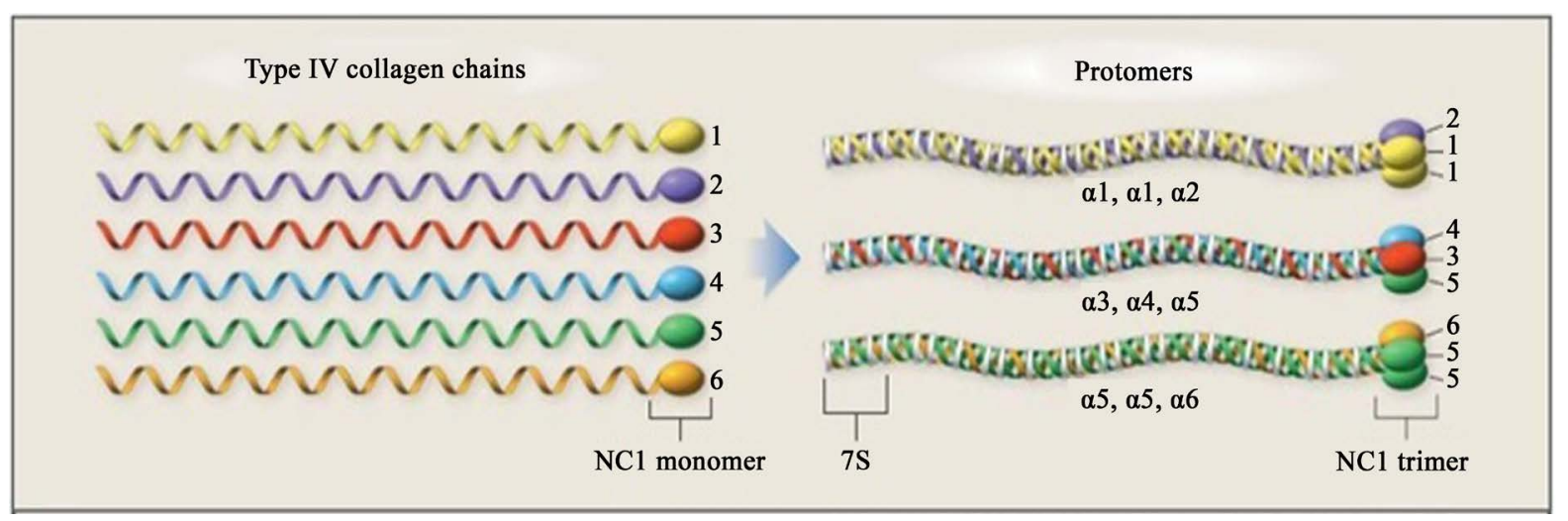

Figure 5. Six genetically distinct $\alpha$ chain are arranged into three triple helical promoters and each promoters has a 7S domain at the N-terminal, the middle of molecules are a long, triple helical collagenous domain, and non-collagenous (NC1) trimmers at the C-terminal (Source: mechanisms of disease. Alport's Syndrome, Goodpasture's Syndrome, and Type IV Collagen (Billy G. Hudson, Ph.D., Karl Tryggvason, M.D., Ph.D., Munirathinam Sundaramoorthy, Ph.D., and Eric G. Neilson, M.D)).

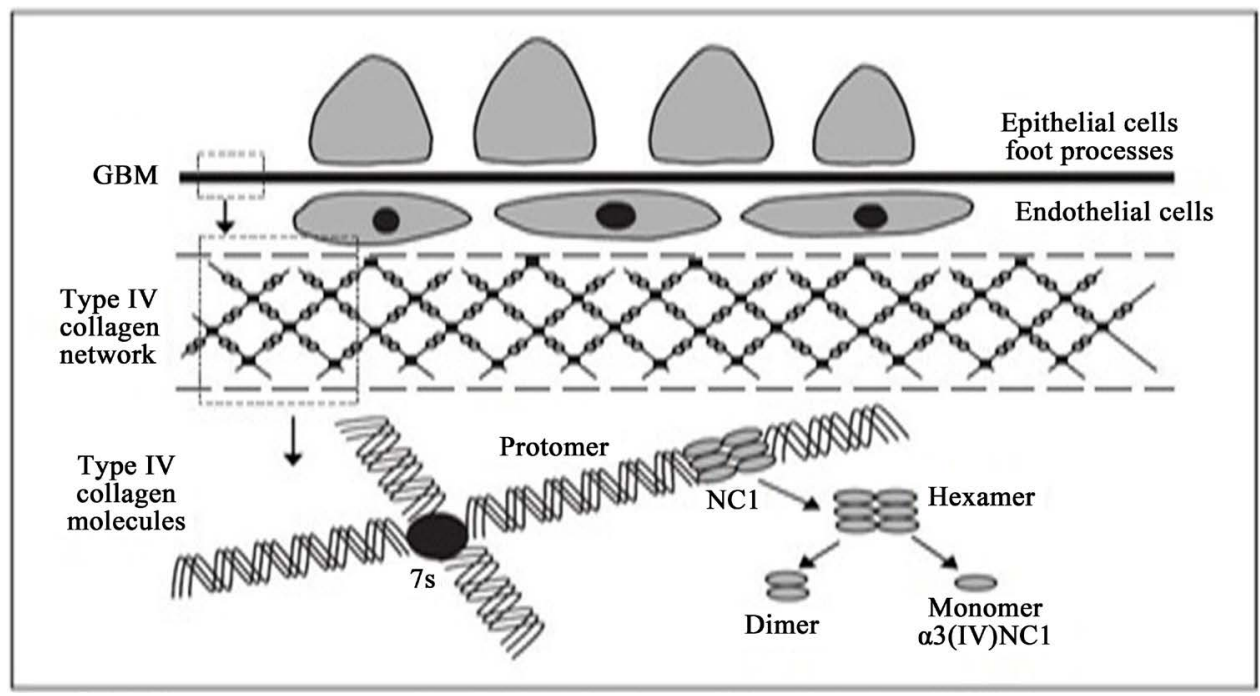

Figure 6. Diagram demonstrating the structure of the glomerular basement membrane, three distinct chain are interwoven to form a triple helix, NC1 domains are placed in head-to-head fashion to form hexamers are connected through 7S domain. Hexamers can be dissociated to form dimer, monomers of NC1 domains that allows to indentify the $\alpha 3$ (IV) NC1 as the autoantigen (Source: Immunology of anti-glomerular basement membrane disease (Alan D. Salama and Charles D. Pusey)). 
antibody, function of molecules, and amplification mechanisms. The Experimental Autoimmune glomerulonephritis, commonly used an animal model of goodpasture's disease that can be induced in animal models by immunization with either collagenous solubilized GBM or the recombinant $\alpha 3$ (IV) NC1 antigen. The EAG is characterized by circulating and deposited anti GBM antibodies, crescent glomerulonephritis and lung hemorrhage [7] [8] [12] [13]. The anti-glomerular basement membrane disease is formed by depositing antibodies that binds to the basement membrane components. The $\alpha 3$ chain of amino terminal, $\alpha 3$ (IV) NC1 domain only can identified by the Experimental autoimmune glomerulonephritis (EAG) in rat, mice, sheep. It is hypothesized, only recombinant antigens contain nine amino acids span in NC1 domain, T cell epitopes. The binding mechanism, identified the mechanism of autoantibodies, the non-collagenous region of $\alpha 3$ chain of type IV collagen domain, humoral and cellular immune mechanism, are still uncovered to lead the further research. Over the past two decades, researchers focused to understand the mechanism of goodpasture epitopes, introduced linear synthetic peptide as well as tried to introduce recombinant proteins expressed on bacterial system to characterize the conformational epitopes [14]-[18]. The recombinant $\alpha 3$ (IV) NC1 have critical role of goodpasture disease. Hellmark et al. [18] and Borza et al. [19] examined 77 sera from goodpasture's patient and showed the third terminal of amino acid of $\alpha 3$ (IV) NC1 bind to the goodpasture antibodies as well as progression of the disease. This in vitro study demonstrated that those epitopes not only bind the goodpasture antibodies but also capable of inducing disease that causes nephritis. However, it is still unraveled, other parts of $\alpha 3$ (IV) chain were necessary to bind antibodies or not so that used full length of recombinant $\alpha 3$ (IV) from mammalian kidney cells. It is clear that Non collagenous domain of $\alpha 3$ (IV) is involved to bind the antibody and conformed the identity of the autoantigen as uniquely the $\alpha 3$ (IV) NC1 [20]. Identified the target epitopes and understand the pathogenesis of process and development the therapeutic strategies in human, the Experimental Autoimmune Glomerulonephritis (EAG) as in rat or mice played an important role model. The original studies demonestred by Steblay [21], sheep immunized with human GBM that developed the crescentric glomerulonephritis. Sado et al. [22] first introduced the Wistar Kyoto (WKY) rats immunized with bovine GBM in FCA developed circulating and depositing anti-GBM in GBM caused cresentic glomerulonephritis. In addition, it was proven by Sado et al. that homologous GBM caused the similar diseases and synthesized the anti-GBM, deposited liear IgG on GBM, deposited of fibrin in the glomeruli, haematuria, albuminauria, focal necrotizing crescentic glomerulonephritis, lung haemorrhage. It is suggested that $\alpha 3$ (IV) NC1 is a major autoantigen in EAG that bind to anti-GBM antibodies from rat type IV collagen, similar result can find in human sera. Therefor WKY rat is a good animal model for analyzing the clinical therapies of kidney diseases. Recently, according to Sado et al. [22], recombinant form of human $\alpha 3$ (IV) NC1 was capable of inducing severe anti-GBM nephritis involved independently in pathogenesis of EAG in WKY rats because it share many characteristics with human diseases. For therapeutic invention is essential for understand the pathogenic mechanisms, therefore using animal model without antibody production, responsible epitopes for EAG in rat by same amino terminal of $\alpha 3$ (IV) NC1 region as the human antibody epitopes. Moreover, $\mathrm{T}$ cells proliferation in vitro without in vivo antibody binding determined that $\mathrm{T}$ cell epitope is responsible for glomerulonephritis disease, crescent glomerulonephritis and fibrin with proteinuria with minimal or absent of IgG. .

\subsection{HEK293 Cell Supernatant, Column Chromatography, SDS-PAGE Gelelectrophrosis, Western Blotting Techniques, Enzyme Linked Immunosorbent Assay (ELISA)}

HEK 293 cells were selected for producing recombinant rat $\alpha 3$ (IV) NC1 antigen because it was consider as an ideal for protein folding, post translation modifications. The HEK 293 cell line is more adherent than parent cell line, easy to work with conditions where recombinant are expressed in media and harvested in to the cell supernatant without transformed cells.

The affinity/column chromatography principle was first described by Cuatrecasas (1972), a method of a mixture of substance is separated from affinity basis by the biological bonding function and now broadly used for protein purification. Anti-FLAG M2 affinity gel is for purification or immunoprecipitation of FLAG fusion proteins.

SDS-PAGE gel electrophoresis is used to separate and detect protein from the mixture of proteins. SDS is an anionic detergent with two hydrophobic tails that can binds the polypeptide chain of protein and separate according to the molecular weight and shape of proteins.

Western blotting techniques is very powerful technique to quantify the target protein. For determine the MW 
of proteins, first separated protein according to the size during gel electrophoresis, detected the specific antibody that bond to the antigen then the essential procedure conform the identification and quantification of antigens.

ELISA is a popular analytical assay to determine the presence of any substance specially antigen. ELISA assay can use to determine how much antibody presence in the serum sample and also how much antigen or protein is bound by an antibody. The antigen-antibody conjugation can determined by $405 \mathrm{~nm}$ ELISA plate reader.

\subsection{Clinical Treatments and Outcomes}

The immune mechanism of glomerulonephritis is related as binding of specific antigen and antibody (B cell) or $\mathrm{T}$ cell (T cell receptor), non-specific tissue damage both cellular and non-cellular, cytokines and inflammation in the glomerulus. Historically immune system of glomerulonephritis was first discovered by deposit of antibody within the glomeruli that could be explained as like antibody mediated mechanisms with either direct reaction of intrinsic glomerular antigens or by depositing antibody in the glomerular basement membrane. Patients with glomerular disease developed biochemical and pathophysiologic disturbance of normal functions of kidney- injury of capillary walls and problem of glomerular and filteration function, excessive loss of hematuria and proteinuria. Due to damage of capillary walls, it causes hypoproteinemia (imbalance of plasma concentration), hypertension/ edma formation (renal handling of $\mathrm{NaCl}$ and water), and finally rapid or slow the Glomerular Filtration Rate (GFR). The syndrome of glomerular disease can be categorized by acute nephritic syndrome, rapidly progressive glomerulonephritis, the nephritic syndrome, symtompless haematuria and proteinuria, slowly progressive chronic nephritis.

The Plasmapheresis and immunosuppression treatment can reduce the circulation of Anti-GBM antibodies of Anti-GBM disease [23]-[25]. The target of this treatment is to decrease of anti-GBM antibodies and ongoing glomerulonephritis. However, it is difficult to predict the patient survival rate or necessity dialysis. Plasmapheresis treatment removes the unbound $\alpha 3$ (IV) NC1 antibodies as well as removal of cytokines, chemokines and other inflammatory modulators. In present medical treatment, use cytotoxic agents stop the new antibodies production by down-regulation of B-cell function [24] [25]. Moreover, Glucocorticoids also decrease the antibodies productions and inflammation of glomerular in kidney. Based on the condition of Anti-GBM patients, initial treatment is high dose oral prednisolone for several months and cyclophosmaide for two to three months. Plasma exchange is another treatment of Anti-GBM diseases that performed daily basis until the anti GBM titer returns its normal concentration. For pulmonary hermorrhage, it is necessary of post-exchange transfusion of fresh frozen plasma. In current study, the patient who has less $435 \mu \mathrm{mol} / \mathrm{L}$ initial creatinine serum, the survival percentage will be $100 \%$ with $95 \%$ survival of renal hemorrhage [26]. The hallmark study is also support this report that $84 \%$ survival for global crescentric glomerulonephritis with $74 \%$ of renal survival [24].

General clinical therapies of some glomerular diseases:

- Minimal Change Glomerulonephritis: In this disease approximately affected $15 \%$ adult and $85 \%$ children, the primary therapy is high dose of prednisone (1 mg per kg, maximum $80 \mathrm{mn}$ ) for minimum 12 weeks, and steroid therapy for 2 months.

- Membranous Nephropathy: $30 \%$ to $40 \%$ adult has been affected due to membranous nephropathy. For this disease, steroids combined with cytotoxic agent for 6 months and mycophenolate therapy is useful for mild risk patients.

- Focal and Segmental glomerulosclerosis: $20 \%$ of adult are affected, therapy is high dose of corticosteroid therapy for at least 6 months for 30\% patients and 70\% patients, who fail to respond steroid treatment, can use cytotoxic agent like cycloportin, cyclophosphamide, or chlorambucil.

- IgA nephropathy (Berger's Disease): Common form of primary glomerular disease mostly affected in Asia and Australia. Corticosteroids are effective for slowing the progressive IgA nephropathy and some studies support use fish oil can slow the progression. In addition, cytotoxic agents can use for rapidly progressive IgA nephropathy.

- Lupus Nephritis: Lupus nephritis is known as paradigmatic immune complex disease. The therapy is high dose of corticosteroids and Cytoxan for immune complex glomerulonephritis and sometimes mycophenolate mofetil is effective for proliferative lupus nephritis.

- Anti-GBM disease and Goodpasture's syndrome: Anti-GBM auto-antibody presence in glomerular capillaries. Clinically demonstrated either isolate renal dysfunction (Anti-GBM disease) or renal disease of pulmonary capillary basement membrane. Therapy is combination of high-dose steroids, Cytoxan and plasmapheresis to remove the anti-GBM. 


\section{Materials and Methods}

\subsection{Expression and Purification of $\alpha 3$ (IV) NC1}

The supplied recombinant rat $\alpha 3$ (IV) NC1 was produced from stably transfected Human Embryonic Kidney (HEK) 293 cells. HEK 293 cells are used for the cDNA expression that cultured by culture media. In the tissue culture laboratory, prepared the culture media first-Dulbeccos Modified Eagle Medium (DMEM) X1 with $50 \mathrm{ml}$ of Fetal Bovine serum, $10 \mathrm{ml}$ of penicillin streptomycin solution, $5 \mathrm{ml}$ of Amphotericin B solution, and $5 \mathrm{ml}$ of G418. After 24 hours, the media was ready to grow the cells and kept it for cell growth for 1 week. Examined the cell growth under microscope and then changed the media for expanded recombinant protein production. Once the cells are 50\% to 70\% confluent, it is required to cell supernatant to harvest the HEK 293 cells. Used 9 supernatant plates and put $25 \mathrm{ml}$ of media with $2.5 \mathrm{ml}$ of cells in every plate and kept in the incubator for growing the cells for $3-4$ days at $37^{\circ} \mathrm{C}$. Observed the cell under microscope, once the confluency is $70 \%-80 \%$ cells, were ready to trypsinization. Removed the media from the plates and added $2 \mathrm{ml}$ trypsin solution with $10 \mathrm{ml}$ media into the tube and centrifuged at $1200 \mathrm{rpm}$ for 8 mins and then took re-suspended cells with fresh $10 \mathrm{ml}$ media and allowed to grow in incubator at $37^{\circ} \mathrm{C}$.

\subsection{Anti-FLAG M2 Affinity Gel and Column Chromatography}

Anti-FLAG affinity gel is used for purification of FLAG-fusion proteins. Once the cells confluence is $70 \%$ $80 \%$, it uses $1 \mathrm{ml}$ of cell with cell lysis buffer (50 mM Tris HCl pH 7.4 with $150 \mathrm{mM} \mathrm{NaCl}, 1 \mathrm{mM}$ EDTA and 1\% Triton X-100). Then washed the adherent cells twice with Phosphate Buffered Saline (PBS) (10 mM phosphate $2.7 \mathrm{mM}$ potassium chloride, $137 \mathrm{mM}$ sodium chloride $\mathrm{pH}$ 7.4) and collected the cells into an appropriate conical centrifuge tube and centrifuged 5 mins and then discard the supernatant and washed with PBS twice and then incubated the cells in incubator. For resin preparation, made $3 \mathrm{~L}$ Tris Buffered Saline (TBS) by (50 mM Tris $\mathrm{HCl}$ with $150 \mathrm{mM} \mathrm{NaCl} \mathrm{pH} \mathrm{7.4)} \mathrm{and} 0.1 \mathrm{M}$ glycine $\mathrm{HCl} \mathrm{pH} \mathrm{3.5.} \mathrm{The} \mathrm{resin} \mathrm{can} \mathrm{stored} 50 \%$ glycerol buffer, however the resin must be removed before equilibration. For purification, removed the necessary resin and then the matrix poured into a clean chromatography column. First rinsed the empty column with TBS solution and then aid in packing the Anti-FLAG M2 affinity gel and make use the gel was uniformly suspended of gel beads and transferred the suspension to the column. For equilibration used $50 \%$ glycerol buffer and continuously wash the gel with TBS solution. It is important to ensure the binding FLAG Fusion protein to the column so that used $0.15 \mathrm{M}$ sodium chloride with neutral $\mathrm{pH}$. Added the rat $\alpha 3$ sample onto the column and filled the column completely and kept 24 hrs. After 24 hrs, washed the column with TBS. Eluted the FLAG fusion protein by acid elution with $20 \mathrm{ml}$ of $0.1 \mathrm{M}$ glycine $\mathrm{HCl}, \mathrm{pH} 3.5$ and gradually put in $1 \mathrm{ml}$ in every 20 tubes. The eluted protein from the resin measured absorbency at $280 \mathrm{~nm}$, using by $1 \mathrm{ml}$ quartz cuvette. The conformation of antigen purification was performed SDS PAGE gel and western blotting techniques.

\subsection{Sodium Dodecyl Sulfate (SDS)-PAGE Gel}

$13.5 \%$ polyacrylamide gels prepared with SDS before analysis the protein. Prepared resolving gels by $3.6 \mathrm{ml}$ acrylamide (30\%) with $1 \mathrm{ml}$ resolving buffer $\mathrm{pH}$ 8.8, SDS (20\%) $40 \mu \mathrm{l}$ with $25 \mu \mathrm{l}$ APS, $2.4 \mathrm{ml} \mathrm{dH}_{2} \mathrm{O}$ and finally added $14 \mu \mathrm{l}$ of TEMED and poured into the glass plates and then quickly added iso-propanol for avoiding air from the gel and kept it around 30 mins. In the meantime, we prepared $4 \%$ stocking gel by $1.07 \mathrm{ml}$ acrylamide with $1 \mathrm{ml}$ stocking buffer, $10 \mu \mathrm{l}$ of SDS (20\%), $1.9 \mathrm{ml}$ of $\mathrm{dH}_{2} \mathrm{O}, 15 \mu \mathrm{l}$ of APS and $7 \mu \mathrm{l}$ of TEMED. After 30 mins washed the plates with distilled water and then put the stocking gel into the plates and after $10-15$ mins inserted the comb and kept another 10 mins. Loaded $20 \mu \mathrm{l}$ of eluted samples for first 8 walls, number $9^{\text {th }}$ wall was loaded with $\alpha 3$ sample and $10^{\text {th }}$ wall loaded with Molecular weight marker or ladder. After finish loading, applied 150 volt and kept it for 2 hours. The next day took out the gels and one gel stained with coomassie blue dyes at room temperature for 20 - 30 mins and then de-stained with $20 \%$ methanol and $10 \%$ acetic acid.

\subsection{Western Blotting Technique}

For western blotting technique, took other SDS page gel and made a transfer sandwich as follows: sponge, filter paper, SDS gel, polyvinylidene fluoride (PDVF) membrane, filter paper, sponge. $1 \mathrm{~L}$ transfer buffer prepared with $100 \mathrm{ml}$ of transfer buffer with $200 \mathrm{ml}$ methanol with $700 \mathrm{ml}$ distilled water. Re-located the sandwich with 
the transfer buffer with ice to maintain $4^{\circ} \mathrm{C}$ temperature and started the electrophoresis for 90 mins. After finished the electrophoresis, took out the membrane and washed it with $1 \%$ of marble and PBS with tween and kept it rocker for 30 mins. Took $5 \mu \mathrm{l}$ sick rat $\alpha 3$ sample and mixed with it $50 \mathrm{ml}$ (PBS + TW), and poured the solution on the membrane and placed in the rocker for 30 mins and then washed again with (PBS + Tw) thrice. The last washed was done by distilled water and then put one tablet to see the bands into membrane.

\subsection{Enzyme-Linked Immunisorbent Assay (ELISA)}

Prepared $5 \mu \mathrm{g} / \mathrm{ml}$ of recombinant rat $\alpha 3$ (IV) NC1 antigen (376 $\mu \mathrm{l}$ of rat $\alpha 3$ mixed with 10ml of carbonate buffer pH 9.6). Took $100 \mu$ l of the mixture and coated each of 96 walls and kept overnight at $4^{\circ} \mathrm{C}$. Washed the plate thrice with PBS/0.001\% Tween and then blocked non-specific binding with $100 \mu$ l blocking buffer, incubated the plate for 60 mins at $37^{\circ} \mathrm{C}$. Then, washed the plate again with (PBS $+\mathrm{Tw}$ ) and added the $100 \mu$ of provided serum 1 and serum 2 in triplicate and incubate the plate for 1 hour. Washed the plated again with PBS and tween three times and then added $10 \mu \mathrm{l}$ of goat anti rat-rat IgG antibody that conjugated to alkaline phosphate at a dilution of 1:1000 and incubated for 1 hour at $37^{\circ} \mathrm{C}$. Again washed the plates (PBS + Tw) and developed the ELISA with the substrate p-nitrophenyl phosphate in the dark for about 10 mins. Took the plate and read the absorbencies for each well at $405 \mathrm{~nm}$ that using an Anthos Multiskan ELISA plate reader. Calculated the results as the as the mean optical density for each triplicate sample.

\section{Results}

\subsection{Design of Recombinant Rat $\alpha 3$ (IV) NC1 Peptide}

The provided literatures review, the required $\alpha 3$ (IV) NC1 domain was obtained from the geneBank protein database. The length of synthetic peptide was 50 amino acids identically. The design of synthetic peptide derived from the rat $\alpha 3$ (IV) NC1 sequence that inducing anti GBM disease in WKY rat. It is determined that the cause of disease was comprised of 15 homologous amino acids of N-terminal direction of the $\alpha 3$ (IV) NC1 collagen domain. The type IV collagen inserted the plasmid pcBFT that encoded a BM40 protein secretion-signal peptide, a hexahistidine tag, sequence of enterokinase cleavage and type IV collagen of 30 amino acids fragment. The main target is to produce the recombinant protein that carries the portion of $\alpha 3$ (IV) NC1 domain containing the anti-GBM antibodies epitopes. This type IV collagen was transfected to the embryonic kidney (HEK) 293 cells (Invitrogen, San Diego, CA) using cell supernatant [27]. HEK 293 cells are suitable to express the recombinant proteins into the cell media without transformed the cells and harvested the cells by cell supernatant. The cells line secreted the recombinant rat $\alpha 3$ (IV) NC1 that were cultured by adding DMEM, fetal bovine serum, penicillin streptomycin solution (Invitrogen with G418 (sigma-Aldrich company Ltd, UK) media. The media cells kept for 48 hours for allowing undisturbed growth. Trypsinisation procedure was done by achieving the overall cell confluence because trypsinisation is an important step of cell culture technique for splitting the adherent cells. Cells typically kept in serum free (conditioned) media in incubator for 5 - 7 days before protein collection. However, the overall cell confluence could not achieve properly because of cell death by fungus infection for incubation problem. The minimal scale of cultured protein excretion conformation was performed by AntiFLAG M2 affinity gel.

\subsection{Purification of Recombinant $\alpha 3$ (IV) NC1 by Column Chromatography Technique}

The epitope tag/FLAG tag or short sequence of amino acids (aa) are commercially recognized of available antibodies, widely used for detection and purification of proteins [28]. Generally, epitope tags are attached at N-terminal, Met-N-terminal, C-terminal. It is useful to detection of protein straightforward by the absent of host cell. FLAG tag contains eight-residue (N-Asp-Try-AspAsp-Asp-Lys-C) hydrophilic peptide tag. This is used for protein purification by affinity/binding media of IgG monoclonal antibody immunized by chromatography resins [29]. The resin was used as a column format at room temperature and added $0.15 \mathrm{M}$ sodium chloride and natural $\mathrm{pH}$ for proper binding of FLAG fusion protein to the Anti FLAG M2 affinity gel. The recombinant $\alpha 3$ loaded onto the column under gravity flow and eluted of bonded FLAG fusion protein by acid elution with glycine (0.1 M glycine $\mathrm{HCl}, \mathrm{pH} 3.5$ of $30 \mu \mathrm{l}$ of $1 \mathrm{M}$ Tris, $\mathrm{pH}$ 8.0). The binding interaction of antigen -antibody depends on the acid elution buffer because it does not affect the protein structure. The eluted protein from the resin were measured at absorbance $280 \mathrm{~nm}$ where higher value of absorbance shown the bonding antigen with M2 an- 
tibody. The value of elution proteins is shown below:

From the elution (Table 1), it shows some discontinuity and all measured value is less than 1 percentage although the higher value of elution means the strong bonding of recombinant $\alpha 3$ antigen with the monoclonal M2 IgG antibody. Now plotted the graph of elution profile of recombinant rat $\alpha 3$ (IV) NC1, the X- axis represents the number of fraction from 1 to 20 and Y-axis represents the optical density of elution measured by $280 \mathrm{~nm}$ wavelength.

According to Figure 7, the highest peak of elution is (0.224) number 2 fractions and then gradually decrease the absorbance value. The reason is that the presence of recombinant antigen and monoclonal M2 antibody binding properties. The purification of affinity tagged proteins, the quantity of target protein can be estimated by

Table 1. Elution profile at $\mathrm{Ab}_{280}$.

\begin{tabular}{cc}
\hline No. of eluent & Absorbency at $\mathbf{2 8 0} \mathbf{~ m m}$ \\
\hline 1 & 0.145 \\
2 & 0.224 \\
3 & 0.088 \\
4 & 0.055 \\
5 & 0.050 \\
6 & 0.046 \\
7 & 0.029 \\
8 & 0.013 \\
9 & 0.017 \\
10 & 0.020 \\
11 & 0.016 \\
12 & 0.018 \\
13 & 0.011 \\
14 & 0.014 \\
15 & 0.017 \\
16 & 0.008 \\
17 & 0.017 \\
18 & 0.014 \\
19 & 0.015 \\
20 & 0.051 \\
\hline &
\end{tabular}

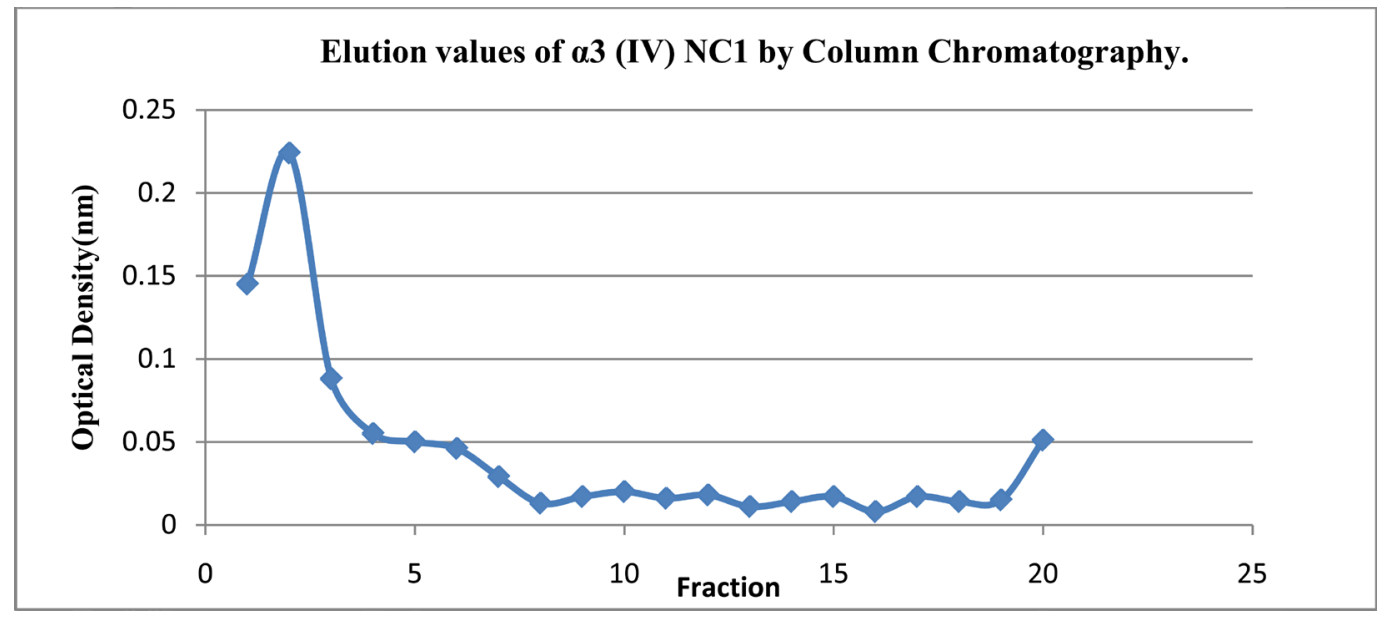

Figure 7. The elution profile of recombinant rat $\alpha 3$ (IV) NC1 at $\mathrm{Ab}_{280}$ wavelength. 
integrated protein peak. The highest peak means the eluted protein has purified. The plotted graph for elution profile shows the nearly linear distribution of antibody-antigen bonding. The second absorbance value shows more purified protein than other elution value. It is important to ensure that any unbounded protein antigen might not be remaining on the antibody affinity column that could lower the columns binding capacity of purification. The verification of presence of antigen and quantified the antigen, took the highest value of elution (first eight elution profile) and performed SDS-PAGE gel electrophoresis and western blotting technique.

\subsection{SDS-PAGE Gel for Visualization and Verifying the Recombinant Protein Purification}

SDS-PAGE analysis is an important protein analysis tool that has generic ability to separate and detect proteins. It is mandatory analytical procedure for protein purification control and monitoring the purification progression as well as identification of contamination of the target protein. Gel electrophoresis of protein purification is widely used for biological purpose such as antigen preparation for antibody generation, identification of $\mathrm{N}$-terminal sequence of amino acid and mass spectrometry. The band identification can be determined by two ways.

1) First, stain a side portion of gel and then align it with unstained portion of gel to determine the specificity of unstained section of gel.

2) Stain the entire gel with negative stain or ladder, exercised the entire bands.

The second step of band identification is useful for eluted protein from the gel matrix.

Proteins are based on the unique net charge, shape, molecular weight where SDS-Page gel electrophoresis is to take the original form of proteins and open them is an essential linear pieces. The reason is that SDS has anionic detergent and each SDS contains two negative charges that binds to all negative charge of proteins so that quantitatively of proteins that gives the linear uniform therefore the separation will be done on their size. The obtained result of SDS analysis is not clear enough to understand the band specifically. The loaded samples took from the highest value of elution profile of affinity column and loaded onto the lane 1 - 8 based on integration and lane 10 was the MW marker or ladder and lane 9 was rat $\alpha 3$ sample. During electrophoresis, all faster moving protein reached at the end of the gel and then stained the gel by cosmassie blue that binds to protein tightly and visualized the immobilized proteins. The relation between mobility and molecular weight is $\log M W=-m x+b$, where $x$ is distance of travel in mm. If the known molecular weight of protein runs with protein of interest, a standard curve can be generated by mobility and standard molecular weight. However, the mobility of distance didn't measure during performing experiment. The image of SDS-PAGE gel is shown below:

The result of SDS PAGE gel electrophoresis (Figure 8) is not clear enough to determine the elute protein's molecular weight as well as antibody of rat $\alpha 3$. The general rule to determinate of unknown protein's molecular weight is after electrophoresis, find the unknown sample's band first that closer to the molecular marker band range (12 kDa - $225 \mathrm{kDa}$ Code: RPN800E) identically. After performing this experiment, the bands were not quite clear however de-stained the gels almost 24 hours for better band identification even though it is hard to measure any of protein's molecular weight. Because of the failure of measurement proteins specification, performed the western blotting technique for better understanding the proteins quantification and detect the proteins.

\subsection{Western Blotting for Quantifying and Identifying Antigen}

Western blotting or immunoblotting or protein blotting, is a technique of detect the specific protein in a complex protein mixture extracted from the cells. In western blotting technique, there are three distinct parts- separation of proteins according to the proteins molecular size by gel electrophoresis, effective transfer from gel to membrane, detection of a target protein using antibody. Denaturing proteins or antigens react with the secondary antibody and visualized the bands. For western blotting, the distinct bands compare to the molecular weight marker that molecular range is from $12 \mathrm{kDa}$ to $225 \mathrm{kDa}$ (Code: RPN800E). According to the molecular weight, it is clear that higher molecular weight means the antigens are strongly bonded to the antibody whereas minimal value of molecular weight of protein has weak bond with the antibody. The image of transfer membrane shows the specific bands that can determine the protein's molecular weight. The lane 1 - 8 are loaded by elute protein, lane 9 is rat $\alpha 3$ and lane 10 is molecular weight of marker or ladder.

The scan copy of transfer membrane (Figure 9), shows quite good band specification. The rat $\alpha 3$ (lane 9) is shown the specific band that near to $76 \mathrm{kDa}$ molecular weight that means the antigen is strongly bonded to the 
antibody. In theoretically, high elution value shows the high molecular weight but the performed result didn't show any specific band. Lane 4 has blue (38 kDa) faint band but lane 1, 2, 3 didn't show any bands at all.

\subsection{ELISA for Antibody Studies of Two Rat Serum Samples}

The recombinant antigen purified by monoclonal antibody based affinity column has showed the high specificity and sensitivity in the detection of normal and sick rat sample serum antibody by Enzyme Linked Immunosorbent Assay (ELISA). ELISA assay is a systematic way to pre-screening the diagnostic of potential recombinant antigen.

Coated the ELISA plate with recombinant $\alpha 3$ (IV) NC1 antigen first, then discarded the antigen plate and added normal and sick serum of antibody that incubated for 1 hours at $37^{\circ} \mathrm{C}$. Then again discarded the remaining

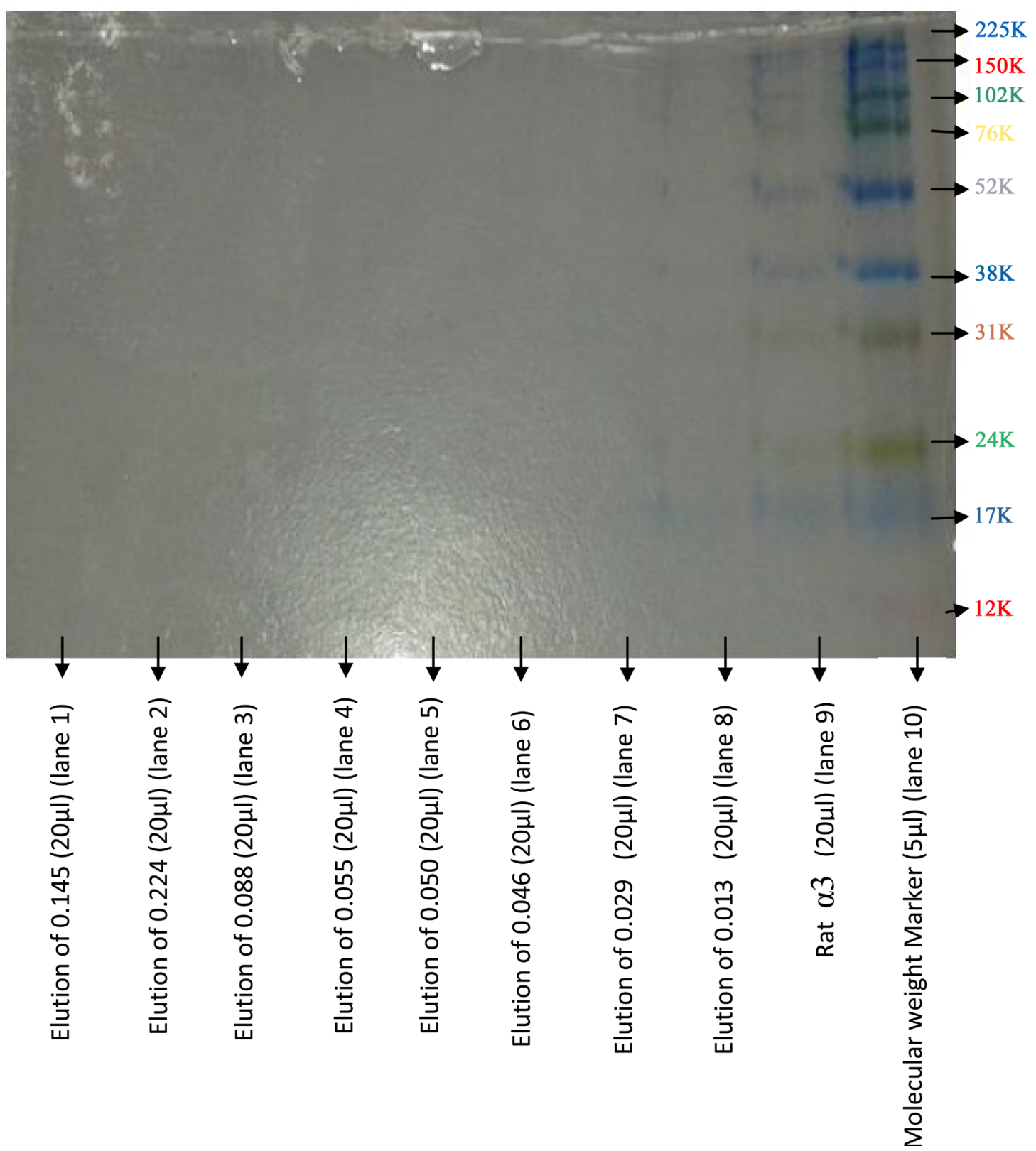

Figure 8. Image of SDS-PAGE gel electrophoresis of various elute protein samples. Lanes 1-8: different protein elution samples, lane 9: Rat $\alpha 3$, lane 10: MW marker or Ladder. The samples were loaded on the top of gel and moved down during electrophoresis. 


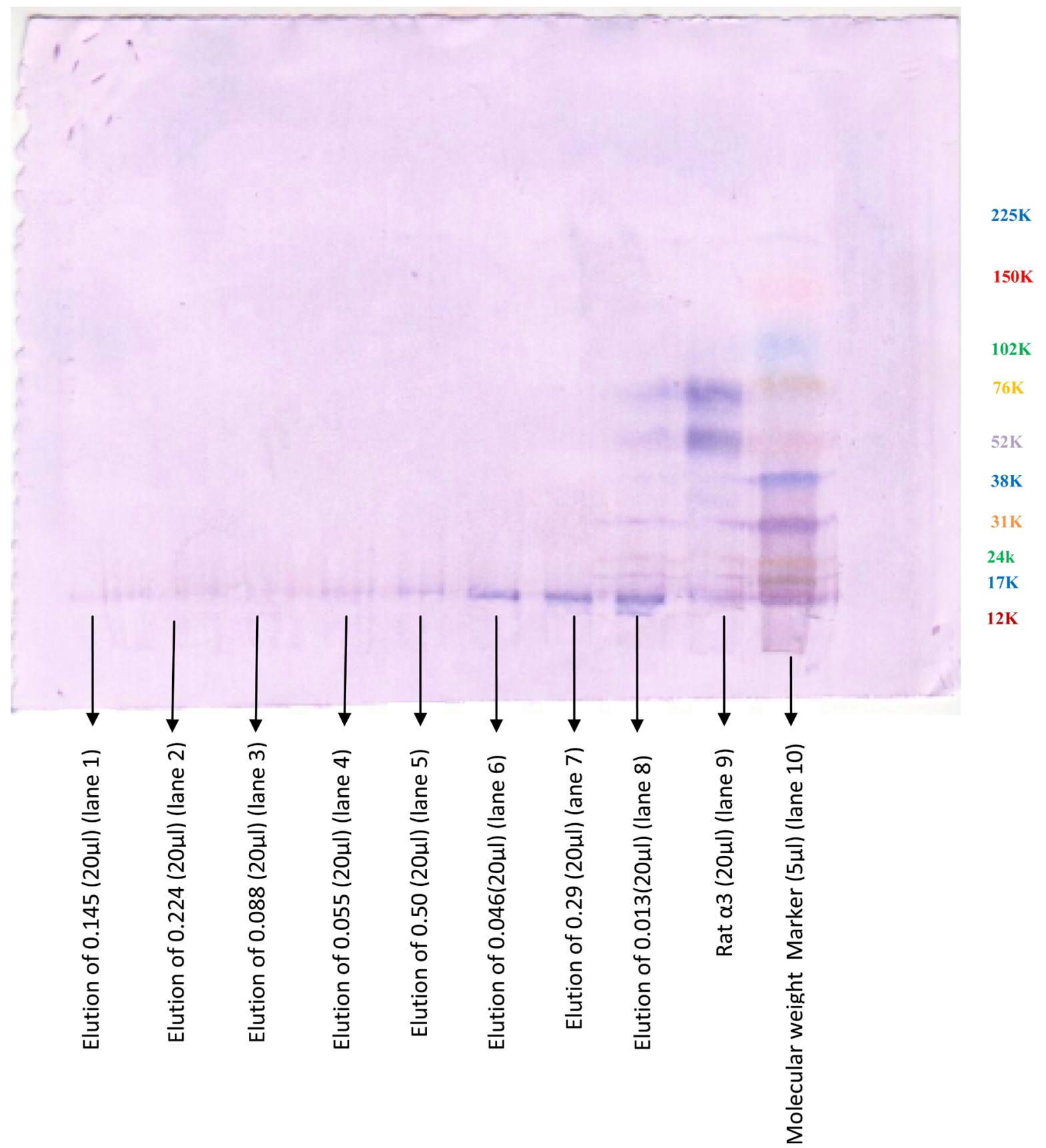

Figure 9. Image of Membrane by Western blotting technique of various elute protein samples range. Lanes 1-8: different protein elution samples, lane 9: Rat $\alpha 3$, lane 10: MW marker or Ladder.

antibody and added secondary antibody goat anti-rat IgG by 1:1000 after 1 hour and then read the absorbance at $405 \mathrm{~nm}$ and calculated the optical density of each triplicate plates.

The optical density of ELISA plate was measured at $405 \mathrm{~nm}$ where lane A and B contains Serum 1 (262/05) sample and lane C and D contain Serum 2 (282/05) sample. The Anthos Multiskan ELISA plate reader shows the absorbance at $405 \mathrm{~nm}$ wavelength.

The value of ELISA plate (Figure 10), shows that the lane A and B has higher absorbance value that lane $\mathrm{C}$ and D. Calculated the mean optical density for each triplicate sample that is shown in below table.

From Table 1 \& Table 2, Reactivity of rat serum from 1 rat and 2 were analyzed by ELISA assay that the serum1 rat sample antibody has strong affinity of recombinant rat $\alpha 3$ (IV) NC1 antigen. The optical density of rat 
serum 1 shows that the dilution of serum concentration of 1:30 has more affinity to binding with the recombinant antigen. The ELISA essay is developed to analyze and determine the sick and normal serum by the quantities comparison of rat serum 1 and 2 where the serum 1 mean optical density $\left(\mathrm{Ab}_{405}\right)$ always high than serum 2 values.

According to the table of 2: the first lane (A) of plate has high optical density (3.13) because of the highest dilution concentration (1:30) of serum. The amount of concentration of serum indicates the presence of antibody so that the highest value of concentration means that the presence of antibody percentage is comparable higher that other dilution. Moreover, the higher concentrated antibody circulation of serum would be higher and the binding affinity to antigens would be higher as well. The value of optical density can measure, which sample has autoanibody that cause glomerulonephritis. In the mean-time, while performing the experiment, the rat serum 1 ELISA plate dilution color was more yellow (depends on dilution concentration) than serum sample 2. The rea-

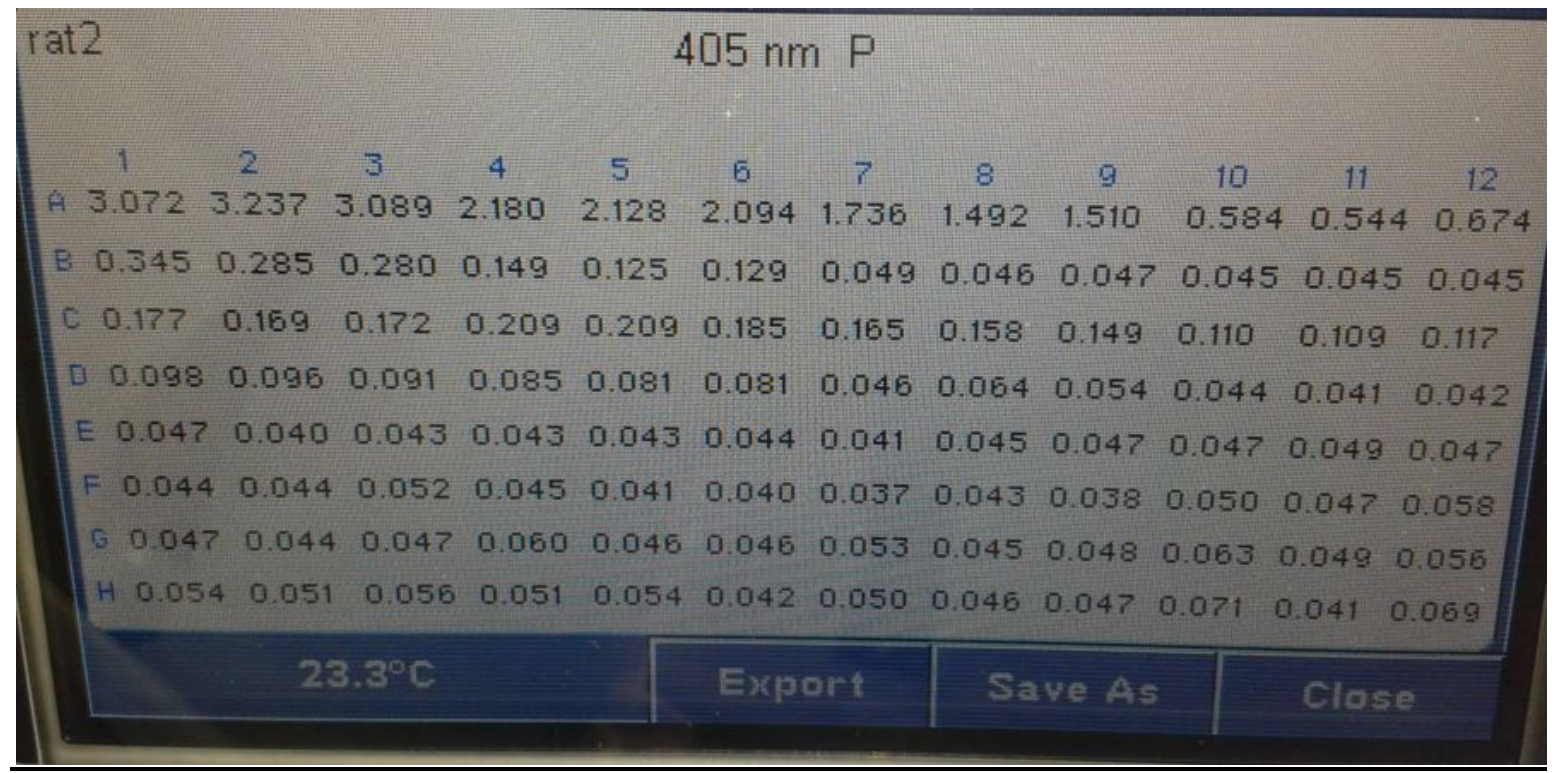

Figure 10. Serum $1(262 / 05)$ and serum $2(282 / 05)$ at $\mathrm{Ab}_{405}$ using by Anthos Multiskan ELISA plate Reader. Lanes A and B indicate the sick sample serum and lanes $\mathrm{C}$ and $\mathrm{D}$ show the normal sample serum.

Table 2. Calculated the results as the mean optical density for each triplicate serum 1 (262/05) rat serum sample.

\begin{tabular}{cccc}
\hline Dilution concentration of each lane & Value of absorbance & Average absorbance (X) & Range $\pm(\mathbf{n}-\mathbf{X})$ \\
\hline & 3.072 & 3.1 & 0.043 \\
A (1:30) & 3.237 & & 0.040 \\
& 3.089 & 2.1 & 0.0873 \\
B (1:100) & 2.180 & & \\
& 2.128 & 1.6 & 0.05607 \\
C (1:300) & 2.094 & & \\
& 1.736 & 0.60 & \\
D (1:1000) & 1.492 & & 0.233 \\
& 0.584 & 0.544 & 0.30 \\
E(1:3000) & 0.674 & 0.345 & 0.0027 \\
\hline
\end{tabular}


son is that the serum 1 has high activity of autoantibody to bind to the antigen and turn to more depth of yellow color. Therefore, the less concentration of serum shows the less binding properties. The result of serum 1 absorbance values is carried out the gradual presence of autoantibody in the supplied sample.

Table 3 consists of rat serum sample 2 with similar dilution factor. The average value of optical density or absorbance at $405 \mathrm{~nm}$ shows the result of presence of autoantibody in the serum. The value of optical density clearly shows that the probability of autoantibody presence is very low. Moreover, the colors of the dilutions remain same rather than yellow color.

Now plot the figure of rat serum sample 1 and 2 where $\mathrm{X}$ axis shows the serum concentration and $\mathrm{Y}$-axis represents the value of optical density at $405 \mathrm{~nm}$.

From Figure 11, the two lines represent the rat serum $1 \& 2$ where the highest value of rat serum 1 obtains the

Table 3. Calculated the results as the mean optical density for each triplicate serum $2(282 / 05)$ rat serum sample.

\begin{tabular}{cccc}
\hline Dilution concentration of each lane & Value of absorbance & Average absorbance $(\mathbf{X})$ & Range $\pm(\mathbf{n}-\mathbf{X})$ \\
\hline & 0.177 & 0.1726 & 0.0033 \\
A (1:30) & 0.169 & & 0.016 \\
& 0.172 & 0.201 & 0.00833 \\
B (1:100) & 0.209 & & 0.003 \\
& 0.209 & 0.15733 & \\
C (1:300) & 0.185 & & 0.165 \\
& 0.158 & & 0.004 \\
D (1:1000) & 0.149 & 0.110 & 0.095 \\
& 0.117 & & 0.0013 \\
\hline
\end{tabular}

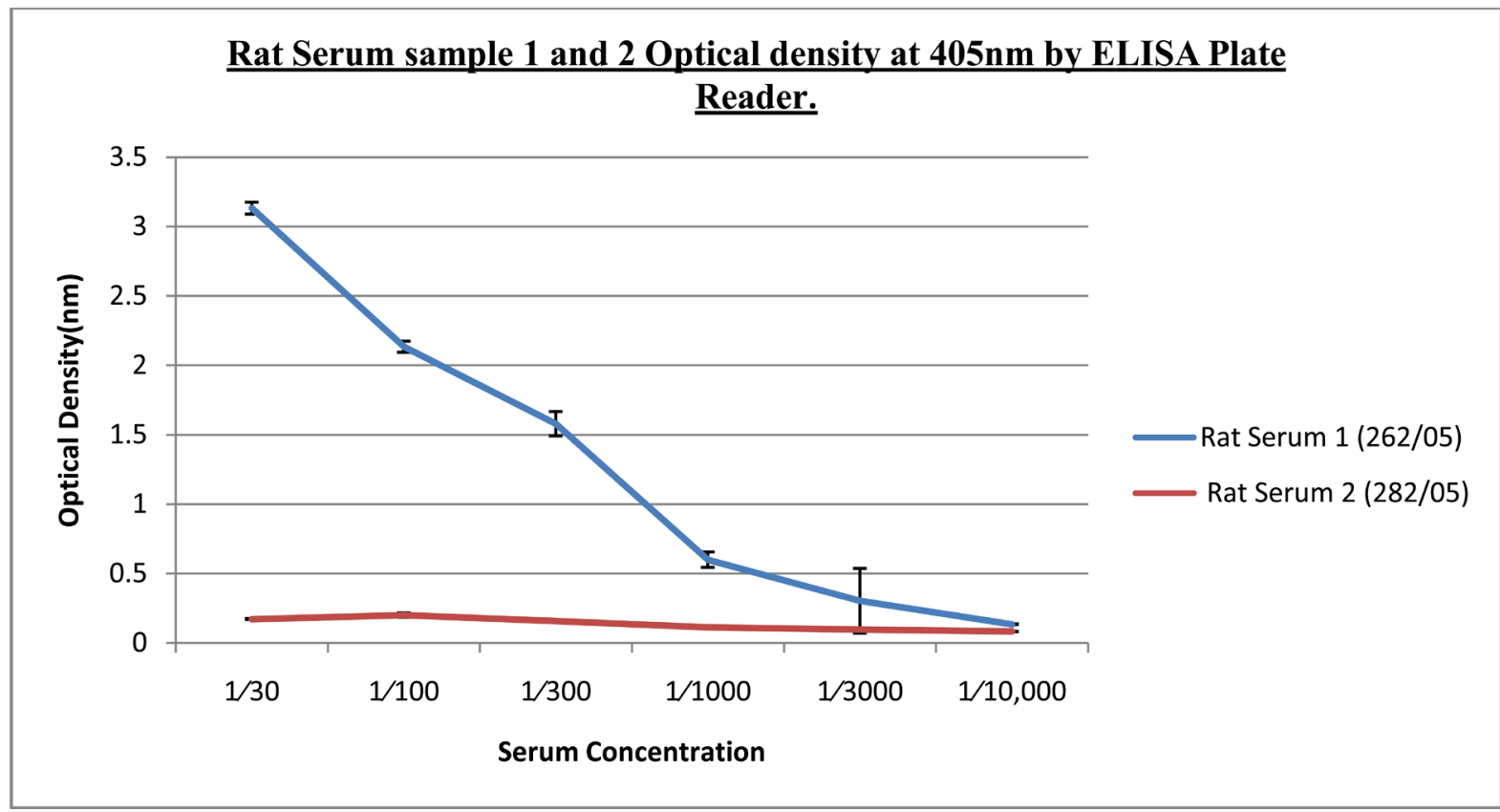

Figure 11. Comparison between rat serum (1 and 2) sample concentration vs. optical density with the error bar. 
pick values than rat serum 2 . The serum 1 sample shows nearly linear distribution of OD value where high concentration (1:30) has highest value and 1:10,000 shows the lowest value of OD. In the serum 2 sample line shows the almost linear liner near to the zero value and also represents error bar. The error percentage of rat serum 1 and 2 is near to zero except the serum 1 of 1:3000 concentrations shows little bit high error percentage.

\section{Discussion}

Glomerulonephritis disease consists of Goodpasture's syndrome with pulmonary hemorrhage causes of circulating and tissue bonding antibodies to the glomerular basement membrane The majority of antibodies activity is in the $\alpha 3$ (IV) NC1 domain [30]-[32] and antigen of NC1 domain can bind to the Anti-GBM autoantibody in basement membrane. The determination of activity is antigen-antibody mechanism, the role of $\alpha 3 \mathrm{NC1}$ in glomerulonephritis with monomers, dimers of $\alpha 3$ chain, immunized with recombinant $\alpha 3$ (IV) NC1 domain [7] [30]-[33]. The serum of goodpasture syndrome is binding the amino terminal of $\alpha 3$ that is responsible of this disease. The investigation was carried out the recombinant rat $\alpha 3$ (IV) NC1 production, cultured antigen, purified antigen, quantified and characterized the antigen.

\subsection{Cell Supernatant for Culture HEK293 Cell Lines and Purification of Recombinant Rat $\alpha 3$ (IV) NC1 by Affinity Column}

The antigen that used in this research was recombinant rat $\alpha 3$ (IV) NC1 domain, transfected the HEK293 cells. Harvested the HEK 293 cells in culture medium and used the HEK 293 cell supernatant for getting the confluent of recombinant $\alpha 3$. Anti FLAG affinity M2 gel was purified IgG monoclonal antibody that used to bind the apllied recombinant $\alpha 3$. Therefore, the purification of $\alpha 3$ (IV) NC1 was done by supernatant affinity chromatography using anti FLAG M2 affinity column (Sigma-Aldrich company ltd) to determine the antibody and antigen conjugation. The literature review of (kidney international, Vol.64, (2003), 2108-2120) [33] and (J Am Soc Nephrol, 16, 1350-1359) [34] obtained, type IV collagen inserted the plasmid pcBFT that encoded a BM40 protein secretion-signal peptide, a hexahistidine tag, sequence of enterokinase cleavage and type IV collagen of 30 amino acids fragment used for the production of recombinant rat $\alpha 3$ (IV) NC1 so that the experimental target is to use recombinant protein that carries the portion of $\alpha 3$ (IV) NC1 domain containing the anti-GBM antibodies epitopes. In tissue culture lab, used cell supernatant for $80 \%-90 \%$ cell confluency but observed the cultured cells under the microscope, it was shown that some of the cells supernatant didn't grow properly because of fungus infection and the problem of incubation temperature. Therefore, the cells confluency percentage was not sufficient enough (30\% - 40\%) however, confluency percentage should be more that $80 \%$.

The affinity column is an antibody that bind to the protein of interest and used for purification. The protein is loaded to the column which binds to the antibody that is retained to the solid support. To get the purified protein from the column, have to break the bond between protein and antibody for this use high concentration of salt or acid elution buffer. While performing this experiment, the value of elution profile shows the gradually decrease because of proper binding of FLAG fusion protein to monoclonal antibody by using $0.1 \mathrm{M}$ Sodium chloride and neutral $\mathrm{pH}$, washed acid elution with $0.1 \mathrm{M}$ glycine $\mathrm{HCl}, \mathrm{pH}$ 3.5. $\mathrm{pH}$ is an important factor for binding because it reduces the nonspecific protein binding to the resin. It is also important to equilibrate the column and buffer before sample application. The unbound antigen that are not bound to the monoclonal antibody was analysed the UV absorbance at $280 \mathrm{~nm}$. The values of all elusions are less than $1 \%$ that means the absorbance of purified recombinant antigen is not enough for analysis. The SDS-PAGE and Western blotting techniques was performed for further confirmation of presence of protein and determined the molecular weight of protein.

\subsection{SDS-PAGE Gel Electrophoresis and Western Blotting Analysis}

The conformation of the eluted protein is $\alpha 3$ (IV) NC1, applied eluted fraction from affinity column by SDSPAGE gel and western blotting techniques, using both an anti-FLAG mAb of FLAG fusion protein epitope and the serum from rat antidbody (analyze by ELISA assay). For SDS-PAGE gel electrophoresis, used first eight elution profile value because the presence of antigen was quite high as well as rat $\alpha 3$ and molecular weight of marker or ladder for quantify and confirmation of antigen. After de-stained the SDS-PAGE gel, the molecular weight of Marker divided into 10 bands and the standard range of band range is $12 \mathrm{kDa}$ to $225 \mathrm{kDa}$ (Code No: RPN800E), however, it is quite difficult to identify the bands of the elutions and rat $\alpha 3$ identically. The reason is that the percentages of the elutions are very low (from affinity analysis) less than 1 . Therefore, may be the bands 
of the elution are not clear enough. In generally, it is expected that the elution of first/second lane would be visualized the significant band due to the elution value but there is no band can identified clearly. The other reason is that, while performing this experiment, it is hard to find the hole of the lane to load the sample, so that it could be mixed with the other volume of solution. The volume of sample solution is quite less only $18 \mu \mathrm{l}$, so the percentage of antigen presence is quite low.

For quantifying the proteins, western blotting is an important essential technique to determine the MW of proteins. According to the membrane image of western blotting technique, the lane 9 was loaded by rat $\alpha 3$ that has one faint band, closer to the $76 \mathrm{kDa}$ (compare to the ladder). The anti-FLAG M2 MAb bond to the recombinant $\alpha 3$ (IV) NC1 is not strong enough although the lane 4 has very thin faint band closer to $52 \mathrm{kDa}$. The reason of difficulty to understand the band is small concentration of elutions, lack of antigen antibody conjugation, and lack of experience of performing the experiment. Therefore, the elution of antigen's molecular weight could not measure perfectly.

\subsection{ELISA Assay for Antigen-Antibody Studies}

The ELISA assay is useful to determine the anti-GBM autoantibody bind to the recombinant rat $\alpha 3$ (IV) NC1 antigen. The supplied two type of rat serum sample $1(262 / 05)$ and rat serum sample $2(282 / 05)$ that contain which may be or may not be contain the disease causes antibody. ELISA assay used for identified which serum contained the anti-GBM autoantibody. The 96 well NUNC plate was coated by recombinant rat $\alpha 3$ (IV) NC1 antigen and then washed with PBS-Tween and blocked the non-specific binding by blocking buffer after that applied different concentration of normal and sick serum and washed again and added 1:1000 dilution of secondary goat anti-rat IgG antibody. The reactivity rat serum sample 1 and 2 was determined by ELISA plate reader of $\mathrm{OD}_{405}$. The non-reactive sample readings were less than one near to zero where the anti- $\alpha 3$ (IV) NC stero-reactivity was consistently higher. The first two lane of plate were shown the high intensity of yellow color whereas the (C\&D) lane kept the normal dilution color. The colour of dilution is one of the ways to measure the activity of antigen-antibody reaction. If the serum contains the disease causes Anti-GBM IgG antibody and that conjugate with the applied recombinant $\alpha 3$ (IV) NC1 antigen, the colour of dilution turns to yellow color. In this consequence, performed ELISA assay, the (A\&B) lane dilution colour was yellow according to the dilution concentration so that the confirmation of sick serum (antibody presence) was in A and B lane. Similarly the C and $\mathrm{D}$ lane remained the original dilution color, therefore, it was proved that the second portion of plate (C \&D) sample collected from normal rat sample.

In addition, the measurement of antibody circulation and activity is not only determined by colour observation but also determined by the absorbance $405 \mathrm{~nm}$ ELISA plate reader techniques. The obtained result of the reading is shown that the first $A$ and $B$ lane of plate has high OD values compare to lane $C$ and $D$. The OD value depends on the dilution concentration so that the first dilution concentration was 1:30 showed the highest value (3.1). Therefore, it is well defined that the highest value of optical density, the highest possibility of antigen and antibody reactivity. The comparison of two set $(\mathrm{A}, \mathrm{B}$ and $\mathrm{C}, \mathrm{D})$ of $\mathrm{OD}_{405}$ value was plotted by line graph where the normal sample of serum is nearly straight line and closer to zero even though the dilution concentration was different but the sick serum sample's OD value has different according to the dilution concentration and the higher the dilution value higher the OD value. In this consequence, it is well understood that the rat serum 1 was collected from sick rat model that contain the disease causing anti-GBM autoantibody. Similarly, the serum sample 2 was collected from normal rat model that has no diseases causing autoantibody.

\section{Conclusion}

It is well defined that how autoimmune disease developed and how antigen binded to the auto antibody. The proposed research outline gives the clear view of recombinant antigen cell culture, characterization and purification by various techniques like HEK293 cell supernatant, affinity chromatography by monoclonal M2 antibody, and SDS-PAGE, western blotting analysis. Understanding the auto immune disease, it will be better to immunize EAG in order to induce Experimental Autoimmune Glomerulonephritis (EAG). However, the experiment was continued only analyzing the recombinant antigen and identified the auto-GBM antibody, did not investigate EAG. In addition, the therapeutic strategies of this disease are still undiscovered. The future work is to investigate how to remove the auto-antibody from serum with antigen-specific or non-antigen specific immune therapy. The antigen specific immune therapy can be designed to restrict immunosuppressive elements that can 
lower the body's immune response because it is noted that a protein antigen can prevent the generation of same antigen. Antigen induced animal model can be helpful to explore the pre-treatment therapy immune disease [35]-[39]. The non-specific immune therapy is cytokines, cell therapy etc. that can boost the antibody's activity to fight the foreign substance.

\section{References}

[1] Salama, A.D. and Pusey, C.D. (2002) Immunology of Anti-Glomerular Membrane Disease. Current Opinion in Nephrology and Hypertension, 11, 279-286. http://dx.doi.org/10.1097/00041552-200205000-00003

[2] Wilson, C.B. and Dixon, F.J. (1973) Anti-Glomerular Basement Membrane Antibody-Induced Glomerulonephritis. Kidney International, 3, 74-89. http://dx.doi.org/10.1038/ki.1973.14

[3] Turner, A.N., Mason, P.J. and Brown, R. (1992) Molecular Cloning of the Human Goodpasture Antigen Demonstrates It to Be the Alpha3 Chain of Type IV Collagen. The Journal of Clinical Investigation, 89, 592-601. http://dx.doi.org/10.1172/JCI115625

[4] Goodpasture, E.W. (1919) The Pathology of Pneumonia Accompanying Influenza. U.S. Naval Medical Bulletin, 13, 177-197.

[5] Stanton, M.C. and Tange, J.D. (1958) Goodpasture’s Syndrome: Pulmonary Hemorrhage Associated with Glomerulonephritis. Australasian Annals of Medicine, 7, 132-144.

[6] Saus, J., Wieslanderm, J. and Langeveld, J.P. (1998) Identification of the Goodpasture Antigen as the Alpha3(IV) Chain of Collagen IV. The Journal of Biological Chemistry, 263, 13374-13380.

[7] Abbate, M., Kalluri, R., Corna, D., Yamaguchi, N., McCluskey, R.T., Hudson, B.G., Andres, G., Zoja, C. and Remuzzi, G. (1998) Experimental Goodpasture’s Syndrome in Wistar-Kyoto Rats Immunized with Alpha3 Chain of Type IV Collagen. Kidney International, 54, 1550-1561. http://dx.doi.org/10.1046/j.1523-1755.1998.00153.x

[8] Ryan, J.J., Reynolds, J., Norgan, V.A. and Pusey, C.D. (2001) Expression and Characterization of Recombinant Rat Alpha3(IV)NC1 and Its Use in the Induction of Experimental Autoimmune Glomerulonephritis. Nephrology Dialysis Transplantation, 16, 253-261. http://dx.doi.org/10.1093/ndt/16.2.253

[9] Hudson, B.G. and Reeders, S.T. (1993) Type IV Collagen: Structure Gene Organization, and Role in Human Diseases, Molecular Basis of Goodpasture and Alport Syndromes and Diffuse Leiomyomatosis. The Journal of Biological Chemistry, 268, 26033-26036.

[10] Borza, D.B., Bondar, O., Colon, S., Todd, P., Sado, Y., Neilson, E.G. and Hudson, B.G. (2000) The Goodpasture Autoantigen. Identification of Multiple Cryptic Epitopes on the NC1 Domain of the Alpha3(IV) Collagen Chain. The Journal of Biological Chemistry, 275, 6030-6037. http://dx.doi.org/10.1074/jbc.275.8.6030

[11] Borza, D.B., Bondar, O., Colon, S., Todd, P., Sado, Y., Neilson, E.G. and Hudson, B.G. (2005) Goodpasture Autoantibodies Unmask Cryptic Epitopes by Selectively Dissociating Autoantigen Complexes Lacking Structural Reinforcement: Novel Mechanisms for Immune Privilege and Autoimmune Pathogenesis. The Journal of Biological Chemistry, 280, 27147-27154. http://dx.doi.org/10.1074/jbc.M504050200

[12] Reynolds, J., Mavromatidis, K., Cashman, S.J., Evans, D.J. and Pusey, C.D. (1998) Experimental Autoimmune Glomerulonephritis (EAG) Induced by Homologous Glomerular Basement Membrane in Two Sub Strains of Wistar-Kyoto Rat. Nephrology Dialysis Transplantation, 13, 44-52. http://dx.doi.org/10.1093/ndt/13.1.44

[13] Hudson, B.G. (1998) Induction of Anti-GBM Nephritis in Rats by Recombinant Alpha3(IV) and Alpha4(IV)NC1 of Type IV Collagen. Kidney International, 53, 664-671. http://dx.doi.org/10.1046/j.1523-1755.1998.00795.x

[14] Hellmark, T., Brunmark, C., Trojnar, J. and Wieslander, J. (1996) Epitope Mapping of Anti-Glomerular Basement Membrane (GBM) Antibodies with Synthetic Peptides. Clinical \& Experimental Immunology, 105, 504-510. http://dx.doi.org/10.1046/j.1365-2249.1996.119808.x

[15] Kalluri, R., Gunwar, S. and Reders, S.T. (1991) Goodpasture Syndrome. Localization of the Epitope for the Autoantibodies to the Carboxyl Terminal Region of the $\alpha 3(\mathrm{IV})$ Chain Basement Collagen. The Journal of Biological Chemistry, 266, 24018-24024.

[16] Kefalides, N.A., Ohno, N. and Wilson, C.B. (1993) Heterogeneity of Antibodies in Goodpasture Syndrome Reacting with Type IV Collagen. Kidney International, 43, 85-93. http://dx.doi.org/10.1038/ki.1993.15

[17] Levy, J.B., Coulhart, A. and Pusey, C.D. (1997) Mapping B Cell Epitopes in Goodpasture’s Disease. Journal of the American Society of Nephrology, 8, 1698-1705.

[18] Hellmark, T., Segelmark, M. and Unger, C. (1999) Identification of a Clinically Relevant Immunodominant Region of Collagen IV in Goodpasture Disease. Kidney International, 55, 936-944. http://dx.doi.org/10.1046/j.1523-1755.1999.055003936.x

[19] Borza, D.B., Bondar, O., Todd, P., Sundaramoorthy, M., Sado, Y., Ninomiya, Y. and Hudson, B.G. (2002) Quaternary 
Organization of the Goodpasture Autoantigen, the Alpha3(IV) Collagen Chain. Sequestration of Two Cryptic Autoepitopes by Intraprotomer Interactions with the Alpha4 and Alpha5NC1 Domains. The Journal of Biological Chemistry, 277, 40075-40083. http://dx.doi.org/10.1074/jbc.M207769200

[20] Leinonen, A., Netzer, K.O. and Boutaud, A. (1999) Goodpasture Antigen: Expression of the Full Length $\alpha 3$ (IV) Chain of Collagen IV and Localization of Epitopes Exclusively of the Noncollagenous Domain. Kidney International, 55, 926-935. http://dx.doi.org/10.1046/j.1523-1755.1999.055003926.x

[21] Steblay, R.W. (1962) Glomerulonephritis Induced in Sheep by Injections of Heterologous Glomerular Basement Membrane and Freund's Complete Adjuvant. The Journal of Experimental Medicine, 116, 253-271. http://dx.doi.org/10.1084/jem.116.2.253

[22] Sado, Y., Naito, I. and Okigaki, T. (1989) Transfer of Anti-Glomerular Basement Membrane Antibody-Induced Glomerulonephritis in Inbred Rats with Isologous Antibodies from the Urine of Nephritic Rats. The Journal of Pathology, 159, 325-332. http://dx.doi.org/10.1002/path.1711580410

[23] Pusey, C.D. (2003) Anti-Glomerular Basement Membrane Disease. Kidney International, 64, 1535-1550. http://dx.doi.org/10.1046/j.1523-1755.2003.00241.x

[24] Yokoyama, H., Wada, T., Zhang, W., Yamaya, H. and Asaka, M. (2007) Advance in Apheresis Therapy for Glomerular Diseases. Clinical and Experimental Nephrology, 11, 122-127. http://dx.doi.org/10.1007/s10157-007-0462-y

[25] Johnson, J.P., Moore Jr., J., Austin, H.A.III, Antonovych, T.T. and Wilson, C.B. (1985) Therapy of Anti-Glomerular Basement Membrane Antibody Disease: Analysis of Prognostic Significance of Clinical, Pathologic and Treatment Factors. Medicine (Baltimore), 64, 219-227. http://dx.doi.org/10.1097/00005792-198507000-00003

[26] Levy, J.B., Turner A.N., Rees, A.J. and Pusey, C.D. (2001) Long Term Outcome of Anti-Glomerular Basement Membrane Antibody Disease Treated with Plasma Exchange and Immunosuppression. Annals of Internal Medicine, 134, 1033-1042. http://dx.doi.org/10.7326/0003-4819-134-11-200106050-00009

[27] Kalluri, R., Danoff, T.M., Okada, H. and Neilson, E.G. (1997) Susceptibility to Anti-Glomerular Basement Disease and Goodpasture's Syndrome Is Linked to MHC Class II Genes and the Emergence of T Cell-Mediated Immunity in Mice. The Journal of Clinical Investigation, 100, 2263-2275. http://dx.doi.org/10.1172/JCI119764

[28] Fritze, C.E. and Anderson, T.R. (2000) Epitope Tagging: General Method for Tracking Recombinant Proteins. Methods in Enzymology, 327, 3-16. http://dx.doi.org/10.1016/S0076-6879(00)27263-7

[29] Einhauer, A. and Jungbauer, A. (2001) The FLAG Peptide, a Versatile Fusion Tag for the Purification of Recombinant Proteins. Journal of Biochemical and Biophysical Methods, 49, 455-465. http://dx.doi.org/10.1016/S0165-022X(01)00213-5

[30] Kalluri, R., Gattone, V.H.II, Noelken, M.E. and Hudson, B.G. (1994) The $\alpha 3$ Chain of Type IV Collagen Induces Autoimmune Goodpasture Syndrome. Proceedings of the National Academy of Sciences of the United States of America, 91, 6201-6205.

[31] Hellmark, T., Johansson, C. and Wieslander, J. (1994) Characterization of Anti-GBM Antibodies Involved in Goodpasture’s Syndrome. Kidney International, 46, 823-829. http://dx.doi.org/10.1038/ki.1994.338

[32] Dehan, P., Weber, M., Zhang, X., Reeders, S.T., Foidart, J.M. and Tryggvason, K. (1996) Sera from Patients with Anti-GBM Nephritis Including Goodpasture’s Syndrome Show Heterogenous Reactivity to Recombinant NC1 Domain of Type IV Collagen Alpha Chains. Nephrology Dialysis Transplantation, 11, 2215-2222. http://dx.doi.org/10.1093/oxfordjournals.ndt.a027139

[33] Chen, L., Hellmark, T. and Bolton, W.K. (2003) Immunodominant Epitopes of $\alpha 3(I V) N C 1$ Induce Autoimmune Glomerulonephritis in Rats. Kidney International, 64, 2108-2120. http://dx.doi.org/10.1046/j.1523-1755.2003.00332.x

[34] Reynolds, J., Prodromidi, I.E., Juggapah, K.J., Abbott, S.D., Holthaus, A.K., Kalluri, R. and Pusy, D.C. (2005) Nasal Administration of Recombinant Rat $\alpha 3$ (IV)NC1 Prevents the Development of Experimental Autoimmune Glomerulonephritis in the WKY Rat. Journal of the American Society of Nephrology, 16, 1350-1359. http://dx.doi.org/10.1681/ASN.2004121026

[35] Myers, L.K., Stuart, J.M., Seyer, J.M. and Kang, A.H. (1989) Identification of an Immunosuppressive Epitope of Type II Collagen That Confers Protection against Collagen-Induced Arthritis. The Journal of Experimental Medicine, 170, 1999-20104. http://dx.doi.org/10.1084/jem.170.6.1999

[36] Gaur, A., Wiers, B., Liu, A., Rothbard, J. and Fathman, C.G. (1992) Amelioration of Autoimmune Encephalomyelitis by Myelin Basic Protein Synthetic Peptide-Induced Anergy. Science, 258, 1491-1494. http://dx.doi.org/10.1126/science.1279812

[37] Mukasa, A., Itoh, M., Tokunaga, Y., Hiramine, C. and Hojo, K. (1992) Inhibition of a Novel Model of Murine Experimental Autoimmune Orchitis by Intravenous Administration with a Soluble Testicular Antigen: Participation of CD8 ${ }^{+}$ Regulatory T Cells. Clinical Immunology and Immunopathology, 62, 210-219. http://dx.doi.org/10.1016/0090-1229(92)90074-X 
[38] Sasamoto, Y., Kawano, Y.I., Bouligny, R., Wiggert, B., Chader, G.J. and Gery, I. (1992) Immunomodulation of Experimental Autoimmune Uveoretinitis by Intravenous Injection of Uveitogenic Peptides. Investigative Ophthalmology \& Visual Science, 33, 2641-2649.

[39] Fuller, B.E., Okayasu, I., Simon, L.L., Giraldo, A.A. and Kong, Y.M. (1993) Characterization of Resistance to Murine Experimental Autoimmune Thyroiditis: Duration and Afferent Action of Thyroglobulin- and TSH-Induced Suppression. Clinical Immunology and Immunopathology, 69, 60-68. http://dx.doi.org/10.1006/clin.1993.1150

\section{Submit or recommend next manuscript to SCIRP and we will provide best service for you:}

Accepting pre-submission inquiries through Email, Facebook, LinkedIn, Twitter, etc.

A wide selection of journals (inclusive of 9 subjects, more than 200 journals)

Providing 24-hour high-quality service

User-friendly online submission system

Fair and swift peer-review system

Efficient typesetting and proofreading procedure

Display of the result of downloads and visits, as well as the number of cited articles

Maximum dissemination of your research work

Submit your manuscript at: http://papersubmission.scirp.org/ 